\title{
The Impact of CKD Anaemia on Patients: Incidence, Risk Factors, and Clinical Outcomes-A Systematic Literature Review
}

\author{
Eirini Palaka, ${ }^{1}$ Susan Grandy, ${ }^{2}$ Heleen van Haalen, ${ }^{3}$ Phil McEwan (iD, ${ }^{4}$ \\ and Oliver Darlington ${ }^{4}$ \\ ${ }^{1}$ Global Payer Evidence, AstraZeneca, Cambridge, UK \\ ${ }^{2}$ Global Payer Evidence, AstraZeneca, Gaithersburg, USA \\ ${ }^{3}$ Global Payer Evidence, AstraZeneca, Gothenburg, Sweden \\ ${ }^{4}$ Health Economics and Outcomes Research Ltd, Cardiff, UK \\ Correspondence should be addressed to Phil McEwan; phil.mcewan@heor.co.uk
}

Received 18 March 2020; Accepted 25 April 2020; Published 1 July 2020

Academic Editor: David B. Kershaw

Copyright (c) 2020 Eirini Palaka et al. This is an open access article distributed under the Creative Commons Attribution License, which permits unrestricted use, distribution, and reproduction in any medium, provided the original work is properly cited.

\begin{abstract}
Anaemia is a common consequence of chronic kidney disease (CKD); however, the risk factors for its development and its impact on outcomes have not been well synthesised. Therefore, we undertook a systematic review to fully characterise the risk factors associated with the presence of anaemia in patients with CKD and a contemporary synthesis of the risks of adverse outcomes in patients with CKD and anaemia. We searched MEDLINE, EMBASE, and the Cochrane Library from 2002 until 2018 for studies reporting the incidence or prevalence of anaemia and associated risk factors and/or associations between haemoglobin ( $\mathrm{Hb}$ ) or anaemia and mortality, major adverse cardiac events (MACE), hospitalisation, or CKD progression in adult patients with CKD. Extracted data were summarised as risk factors related to the incidence or prevalence of anaemia or the risk (hazard ratio (HR)) of outcome by $\mathrm{Hb}$ level $(<10,10-12,>12 \mathrm{~g} / \mathrm{dL})$ in patients not on dialysis and in those receiving dialysis. 191 studies met the predefined inclusion criteria. The risk factor most associated with the prevalence of anaemia was CKD stage, followed by age and sex. Mean HRs $(95 \% \mathrm{CI})$ for all-cause mortality in patients with CKD on dialysis with $\mathrm{Hb}<10,10-12$, and $>12 \mathrm{~g} / \mathrm{dL}$ were 1.56 (1.43-1.71), 1.17 (1.09-1.26), and $0.91(0.87-0.96)$, respectively. Similar patterns were observed for nondialysis patients and for the risks of hospitalisation, MACE, and CKD progression. This is the first known systematic review to quantify the risk of adverse clinical outcomes based on $\mathrm{Hb}$ level in patients with CKD. Anaemia was consistently associated with greater mortality, hospitalisation, MACE, and CKD progression in patients with CKD, and risk increased with anaemia severity. Effective treatments that not only treat the anaemia but also reduce the risk of adverse clinical outcomes are essential to help reduce the burden of anaemia and its management in CKD.
\end{abstract}

\section{Introduction}

The worldwide prevalence of chronic kidney disease (CKD) is estimated to be $8-16 \%$ [1] and continues to grow, driven by ageing populations and increasing rates of obesity and type 2 diabetes mellitus. Type 2 diabetes and hypertension are the leading causes of CKD in the developed world [1], and the presence of CKD increases san individual's risk of developing cardiovascular (CV) disease, hyperlipidaemia, mineral and bone disorders, and anaemia [2]. Anaemia-defined by the World Health Organization (WHO) as a blood $\mathrm{Hb}$ concentration of $<12 \mathrm{~g} / \mathrm{dL}$ for nonpregnant adult women and $<13 \mathrm{~g} / \mathrm{dL}$ for adult men [3] —is characterised by insufficient red blood cells and therefore haemoglobin $(\mathrm{Hb})$, and common signs/symptoms include a pale appearance, fatigue, and dyspnoea (breathlessness).

The development of anaemia in patients with CKD is driven by at least two factors. First, compared with patients without CKD, those with CKD produce less erythropoietin (EPO), a hormone produced by the kidneys that stimulates red blood cell production [4], and second, hepcidin-a hormone that (at high levels) impairs dietary iron 
absorption-is elevated in patients with CKD [5]. Iron is an essential component of $\mathrm{Hb}$ and is therefore necessary for oxygen transport. Whilst it is well established that that the presence of anaemia in patients with CKD is associated with poorer quality of life [6] and increased risks of adverse clinical outcomes [2], no known systematic literature reviews (SLRs) or meta-analyses have quantified the risk of adverse clinical outcomes against the severity of anaemia. Therefore, we sought to review the literature to better understand the risk factors associated with the prevalence of anaemia in patients with CKD treated according to standard of care and to quantify the associations between anaemia (or $\mathrm{Hb}$ concentration) and the risks of patient mortality, hospitalisation, major adverse cardiac events (MACE), or CKD progression.

\section{Methods}

2.1. Literature Search and Data Extraction. A SLR was conducted according to the Preferred Reporting Items for Systematic review and Meta-Analysis Protocols (PRISMAP) checklist [7]. Searches were conducted to include studies published between 01 January 2002 and 31 August 2018 across the following electronic databases: PubMed (MEDLINE and MEDLINE In-Process), EMBASE, and the Cochrane Library. The electronic search strategies for each of the databases are included in the Supplementary Material (available here). In addition to the searching of databases and conference proceedings, a free text Internet search was conducted and reference lists from relevant studies were used to identify further studies that may meet eligibility criteria. Search strategies for each database are detailed in Supplementary Tables S1-S3.

Bibliographic details and abstracts of all citations retrieved by the literature search were downloaded into Endnote version X7. Titles and abstracts were independently assessed for eligibility by two reviewers. Full texts of potentially eligible studies were retrieved and assessed against the Population-Intervention-Comparators-OutcomesStudy (PICOS) eligibility criteria (Table 1) independently by two reviewers. Any discrepancies between the two reviewers concerning eligibility were resolved by consensus.

The inclusion criteria captured studies describing the incidence or prevalence of anaemia alongside associated risk factors and/or associations between $\mathrm{Hb}$ or anaemia and mortality, MACE, hospitalisation, or CKD progression in adult patients with CKD on dialysis or adult patients with CKD not on dialysis. "Associations" included all studies that reported relative or absolute measures of risk for mortality, hospitalisation, MACE, and CKD progression dependent on a patient's $\mathrm{Hb}$ level or the presence of anaemia and were reported in terms of event incidence rate, probability of event, hazard ratio (HR), odds ratio (OR), relative risk ratio (RR), and incidence rate ratios (IRRs), irrespective of significance. Most studies reported measures of risk adjusted for baseline demographics and comorbidities, and the most adjusted measure was extracted for analysis. MACE included cardiovascular events, stroke, coronary heart (or artery) disease, heart failure, myocardial infarction, and atrial fibrillation. Studies conducted in paediatric patients or those reported in languages other than English were excluded. Data from studies that met the inclusion criteria were extracted by a single reviewer and quality-checked by a second reviewer. Due to wide heterogeneity in study design across the included studies, a quality assessment was not performed.

2.2. Analysis. Extracted data were tabulated to identify frequently reported risk factors associated with the development of anaemia in patients with CKD. Risk factors were grouped into broader categories for reporting, and those identified by more than one study were displayed graphically; however, due to heterogeneity of risk factor definitions within these categories, no formal quantitative analysis is presented regarding the relative magnitude of the effects of these risk factors on the incidence of adverse clinical outcomes.

A random-effects meta-analysis of the effects of $\mathrm{Hb}$ concentration on the risks of all-cause mortality, CV specific mortality, MACE, hospitalisation, and CKD progression (defined as progressing to end-stage renal disease (ESRD) or the initiation of renal replacement therapy (RRT)) was conducted for studies reporting outcomes of interest in patients with CKD not on dialysis and patients with CKD receiving dialysis. Note that CKD progression was only assessed in patients with CKD not on dialysis. The metaanalysis was conducted using $\mathrm{R} 3.4 .0$ [8] and the package meta [9] to account for study sample sizes and reported estimates of uncertainty.

To enable more consistent analysis of reported associations between $\mathrm{Hb}$ concentration and patient adverse outcomes (i.e., mortality, MACE, hospitalisation, and CKD progression), $\mathrm{Hb}$ concentration categories were converted to a single $\mathrm{Hb}$ value for analysis using the midpoint of the categorical range. Hb was grouped into the following categories for analysis: $<10 \mathrm{~g} / \mathrm{dL}$, $10-12 \mathrm{~g} / \mathrm{dL}$, and $>12 \mathrm{~g} / \mathrm{dL}$, and risk of each outcome attributed to each $\mathrm{Hb}$ grouping where data were available. If a study reported $\mathrm{Hb}$ without a defined lower limit (e.g., $<9 \mathrm{~g} / \mathrm{dL}$ ), the upper defined limit minus $1 \mathrm{~g} / \mathrm{dL}$ (i.e., $8 \mathrm{~g} / \mathrm{dL}$ ) was applied to that category prior to inclusion into the overall analysis. Similarly, if a study reported $\mathrm{Hb}$ without a defined upper limit (e.g., >13 g/dL), the lower defined limit plus $1 \mathrm{~g} / \mathrm{dL}$ (i.e., $14 \mathrm{~g} /$ dL) was applied to that category prior to inclusion into the overall analysis. Where definitions of anaemia were not provided, a threshold value of $10 \mathrm{~g} / \mathrm{dL}$ was assumed for anaemic patients and a threshold value of $13 \mathrm{~g} / \mathrm{dL}$ was assumed for nonanaemic patients. Reference categories for relative measures of risk are as reported in their respective publications, and point estimates presented are based on the aggregation of relative measures of risk reported for each $\mathrm{Hb}$ category. Reported absolute measures of risk were converted to the corresponding relative measure for meta-analysis, using the highest $\mathrm{Hb}$ category as a reference.

The risk of each outcome was also expressed based on continuous $\mathrm{Hb}$ data (per $1 \mathrm{~g} / \mathrm{dL}$ increase in $\mathrm{Hb}$ ). Data reported are means (95\% confidence interval (CI)). All reported estimates of associations between $\mathrm{Hb}$ or anaemia and 
TABle 1: PICOS eligibility criteria for the identification of studies.

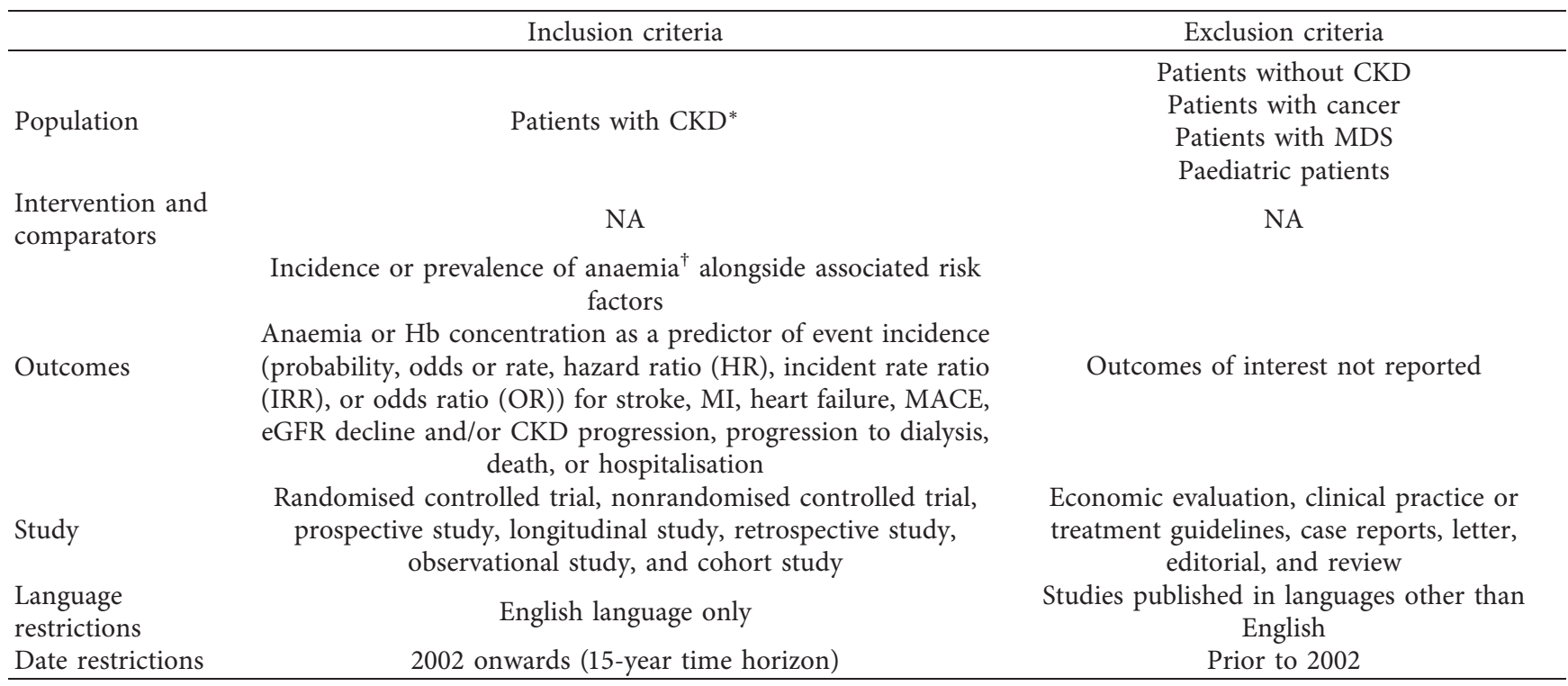

CKD: chronic kidney disease; ESRD: end-stage renal disease; Hb: haemoglobin; HR: hazard ratio; IRR: incident rate ratio; MACE: major adverse cardiovascular events; MDS: myelodysplastic syndrome; MI: myocardial infarction; NA: not applicable; OR: odds ratio. ${ }^{*}$ Patients with comorbidities were included, with the exception of CKD patients with cancer or MDS. ${ }^{\dagger}$ Anaemia was defined as low Hb in the blood or low red blood cell production. Other types of anaemia such as chemotherapy-induced anaemia and sickle cell anaemia were excluded.

patient outcomes were included in the analysis regardless of statistical significance.

\section{Results}

3.1. Summary of Included Studies. The searches identified 3734 references, after the removal of duplicates. After reviewing titles and abstracts, a further 2728 references were excluded. Full texts of the remaining 1006 references were retrieved and reviewed. Following full-text review, 191 references were deemed to satisfy the inclusion criteria and data were subsequently extracted for analysis (Figure 1). Of the 815 studies excluded following full-text review, 637 studies were excluded for not including variables (i.e., the use of haematocrit or red blood cell width distribution instead of $\mathrm{Hb}$ or the reporting of incidence or prevalence without associated risk factors) or outcomes (i.e., the risk of outcome was not reported in association with anaemia) of interest. Furthermore, 88 were conducted in non-CKD populations, 56 were excluded due to study design, and five were reported in languages other than English.

From the 191 included studies (Table 2), 75 were prospective, 65 were retrospective, 11 were observational, and 11 were randomised controlled trials; the design was unspecified in 29 studies. Total cohort sizes ranged from 50 to $1,136,201$. Sixty-six of the included studies were conducted in Asia, 62 in North America, 48 in Europe, five in South America, four in Africa, two in Australia, and four were multinational. The majority of studies were conducted in either outpatient/renal clinic $(n=67)$ or hospital settings $(n=56)$, with small numbers undertaken in the community $(n=10)$; the setting was not reported in 58 studies.
3.2. Risk Factors Associated with Anaemia. The incidence or prevalence of anaemia was reported in 32 studies; prevalence was reported in $n=30$, and incidence was reported in $n=2$. 23 studies were conducted in CKD patient cohorts not on dialysis, one study in a dialysis cohort, and eight studies in cohorts that included both nondialysis and dialysis patients with CKD. There was significant heterogeneity in the definition of anaemia used across the included studies; however, there was no trend in of the use of different $\mathrm{Hb}$ thresholds over time in line with changing recommendations. Whilst the most common definition of anaemia aligned with $\mathrm{WHO}$ guidelines for the diagnosis of anaemia [3], of $\mathrm{Hb}$ levels $<13.0 \mathrm{~g} / \mathrm{dL}$ in men and $<12.0 \mathrm{~g} / \mathrm{dL}$ in women $(n=13)$, thresholds ranged between $10.0 \mathrm{~g} / \mathrm{dL}$ and $13.5 \mathrm{~g} / \mathrm{dL}$ for men and $10.0 \mathrm{~g} / \mathrm{dL}$ and $12.0 \mathrm{~g} / \mathrm{dL}$ for women. Furthermore, not all studies reported separate thresholds for men and women. Risk factors associated with the presence of anaemia reported by more than one study are shown in Figure 2. The most frequently identified risk factor was eGFR or CKD stage $(n=30)$, followed by age $(n=10)$, sex $(n=10)$, race/ ethnicity $(n=5)$, and albuminuria $(n=5)$. In all of these cases, patients with more severe renal impairment were at increased risk of experiencing anaemia.

\subsection{Associations between Haemoglobin and Adverse Clinical Outcomes}

3.3.1. Association between Haemoglobin and Mortality. An association between $\mathrm{Hb}$ concentration (or anaemia) and mortality was reported by 124 studies, with 42 studies conducted in CKD patient cohorts not on dialysis, 76 studies in dialysis cohorts, and six studies in cohorts that included both nondialysis and dialysis patients with CKD. One 


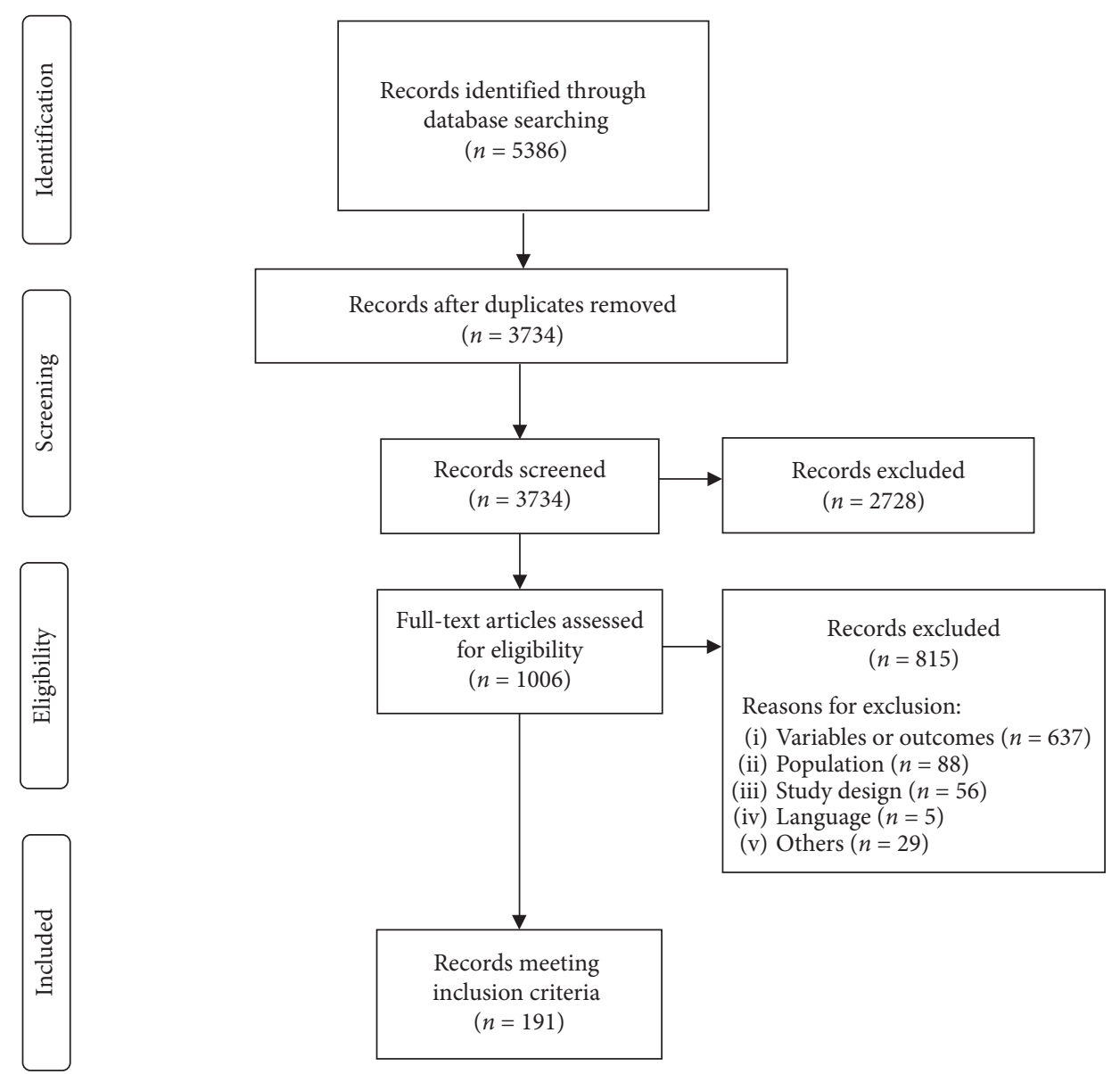

FIgURE 1: PRISMA flow diagram.

hundred and nineteen and 13 studies identified similar relationships between $\mathrm{Hb}$ or anaemia and both all-cause mortality and CV mortality, respectively. Pooled mean HRs quantifying the risk of both all-cause and CV mortality based on $\mathrm{Hb}$ concentration are shown in Figure 3.

Pooled mean (95\% CI) HRs for the risk of all-cause mortality in patients with CKD not on dialysis with $\mathrm{Hb}<10 \mathrm{~g} /$ $\mathrm{dL}(n=17)$ and $10-12 \mathrm{~g} / \mathrm{dL}(n=1)$ were $1.70(1.42-2.01)$ and 0.97 (0.92-1.01), respectively. No studies reported the risk of all-cause mortality in patients with CKD not on dialysis with $\mathrm{Hb}>12 \mathrm{~g} / \mathrm{dL}$. The HR of CV mortality in patients with CKD not on dialysis with $\mathrm{Hb}<10 \mathrm{~g} / \mathrm{dL}$ was only reported by one study, with a median HR of 3.72 and wide CIs of 1.72 to 8.05.

The estimated HRs of all-cause mortality in patients with CKD on dialysis with $\mathrm{Hb}<10 \mathrm{~g} / \mathrm{dL}(n=11), 10-12 \mathrm{~g} / \mathrm{dL}$ $(n=15)$, and $>12 \mathrm{~g} / \mathrm{dL}(n=8)$ were $1.56(1.43-1.71), 1.17$ (1.09-1.26), and 0.91 (0.87-0.96), respectively. The HRs of CV mortality in dialysis patients followed a similar pattern with HRs of $1.50(1.32-1.70), 1.24(1.09-1.40)$, and 1.00 (0.95-1.06) across $\mathrm{Hb}<10 \mathrm{~g} / \mathrm{dL}(n=4), 10-12 \mathrm{~g} / \mathrm{dL}(n=7)$, and $>12 \mathrm{~g} / \mathrm{dL}(n=4)$, respectively.

The HR of all-cause mortality and CV mortality when $\mathrm{Hb}$ concentration was reported as a continuous variable followed similar patterns to the categorical data, of decreasing risk with increasing Hb. Mean (95\% CI) HRs for the overall risk of all-cause mortality in patients with CKD not on dialysis $(n=18)$ and on dialysis $(n=33)$ were 0.93 (0.91-0.95) and $0.86(0.83-0.89)$ per $1 \mathrm{~g} / \mathrm{dL}$ increase in $\mathrm{Hb}$, respectively. The HR of CV mortality per $1 \mathrm{~g} / \mathrm{dL}$ increase in Hb was $0.70(0.52-0.94)$ and $0.87(0.81-0.94)$ in patients with CKD not on dialysis $(n=1)$ and on dialysis $(n=1)$, respectively.

3.3.2. Association between Haemoglobin and Hospitalisation. An association between $\mathrm{Hb}$ concentration (or anaemia) and hospitalisation was reported in 22 studies, with seven studies conducted in CKD patient cohorts not on dialysis, 14 studies in dialysis cohorts, and one study in a cohort that included both patients CKD not on dialysis and patients on dialysis. Mean HRs quantifying the risk of hospitalisation based on $\mathrm{Hb}$ concentration are shown in Figure 4 (left).

The pattern of association between $\mathrm{Hb}$ (or anaemia) and hospitalisation observed in the included studies tended to be similar to that observed between $\mathrm{Hb}$ and mortality, with lower $\mathrm{Hb}$ associated with higher risk of hospitalisation.

The pooled mean (95\% CI) HR for the risk hospitalisation in CKD patients not on dialysis with $\mathrm{Hb}<10 \mathrm{~g} / \mathrm{dL}(n=2)$ was 1.46 (1.02-2.09). No studies reported the risk of hospitalisation in CKD patients not on dialysis with $\mathrm{Hb}$ of $10-12 \mathrm{~g} / \mathrm{dL}$ or $>12 \mathrm{~g} / \mathrm{dL}$. The HR of hospitalisation in patients on dialysis with $\mathrm{Hb} \quad 10-12 \mathrm{~g} / \mathrm{dL} \quad(n=2)$ and $>12 \mathrm{~g} / \mathrm{dL} \quad(n=2)$ were 1.09 


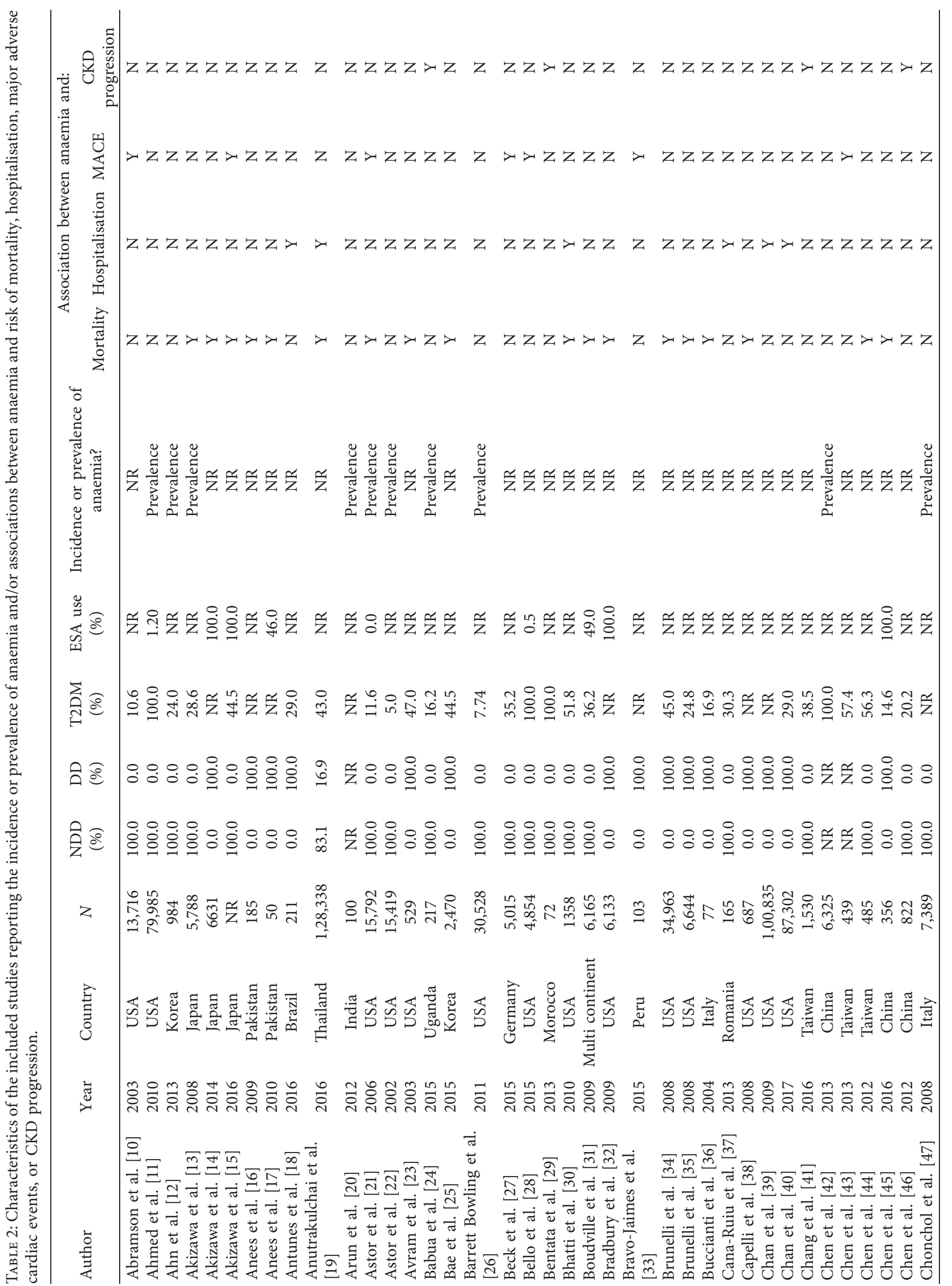




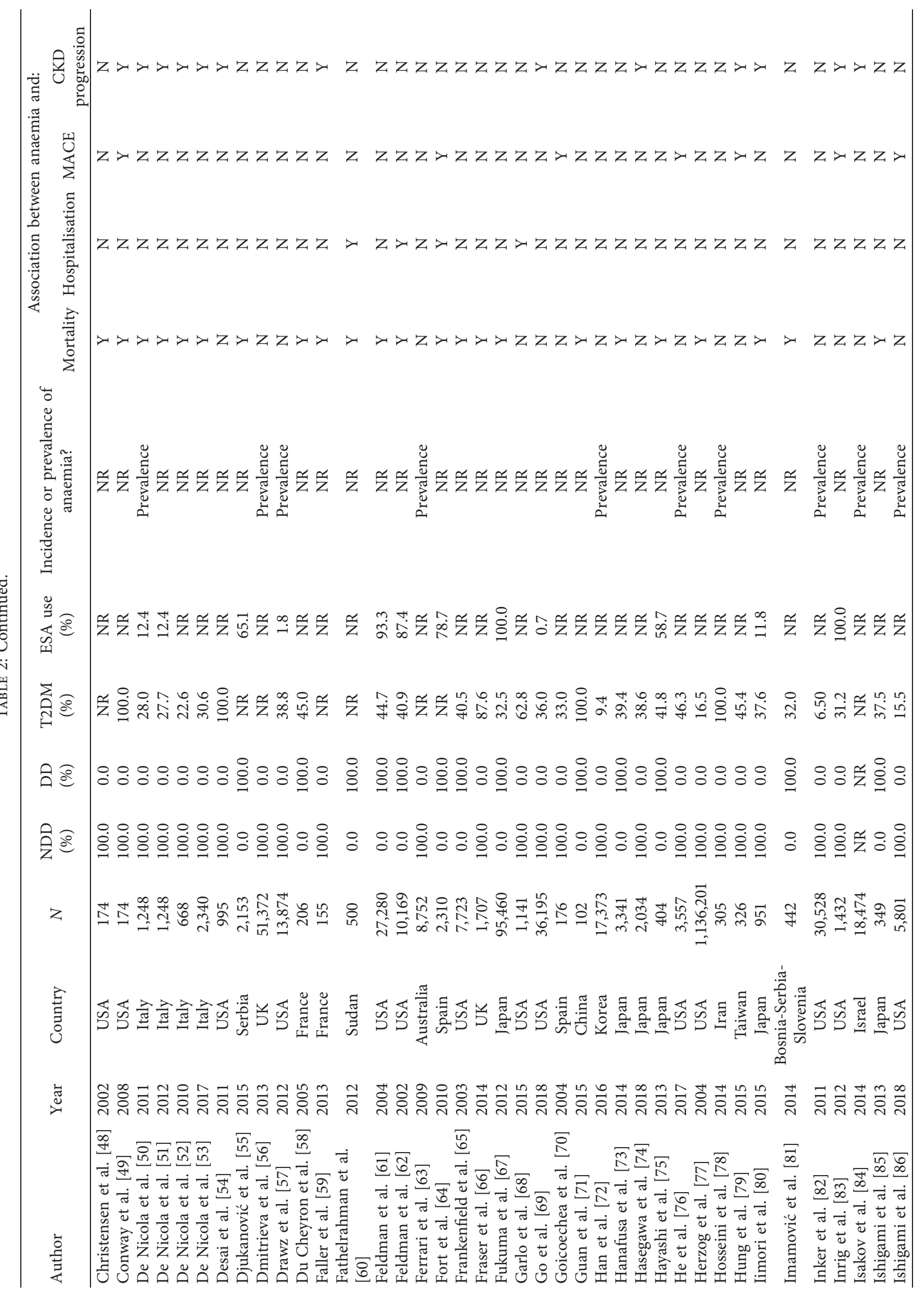




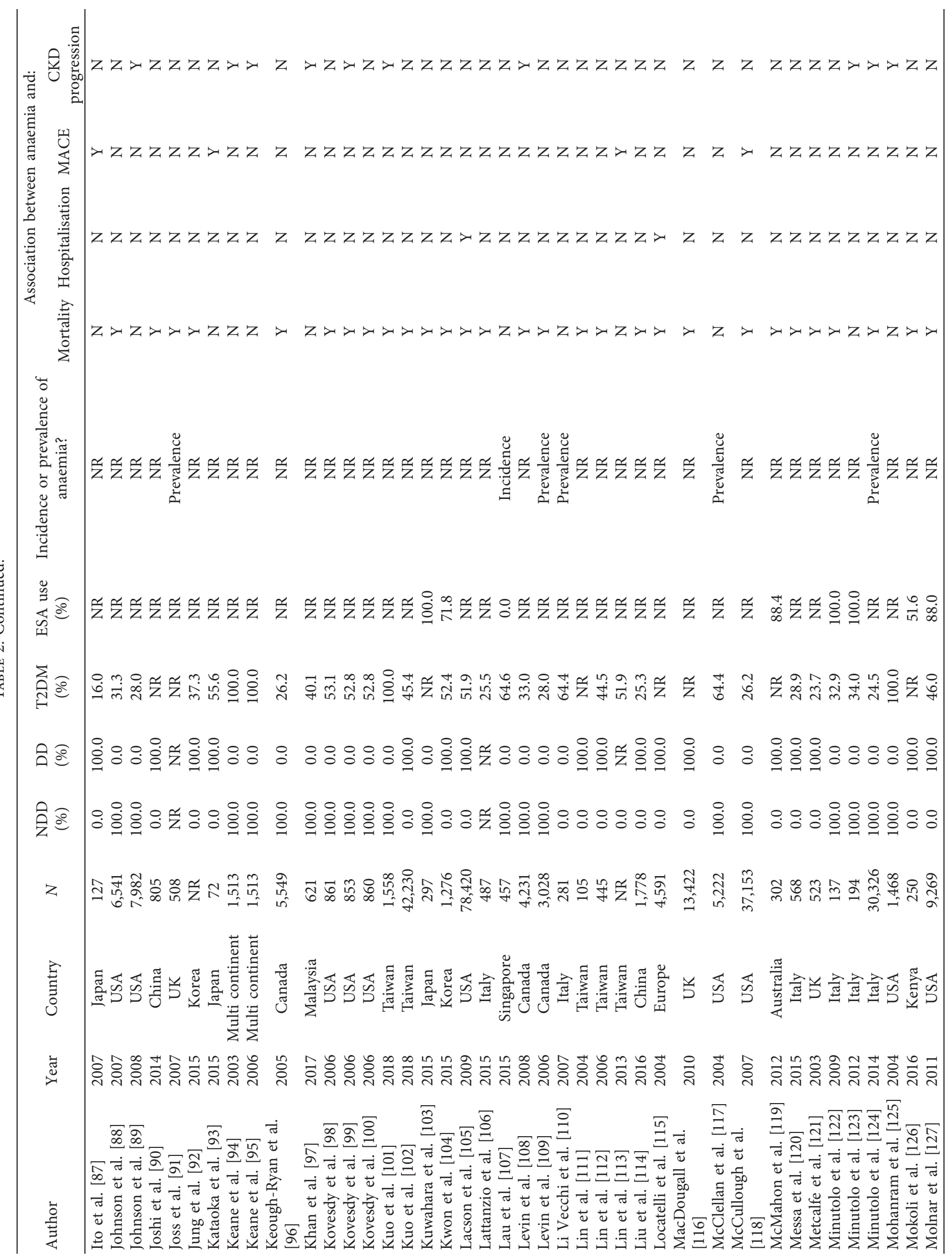




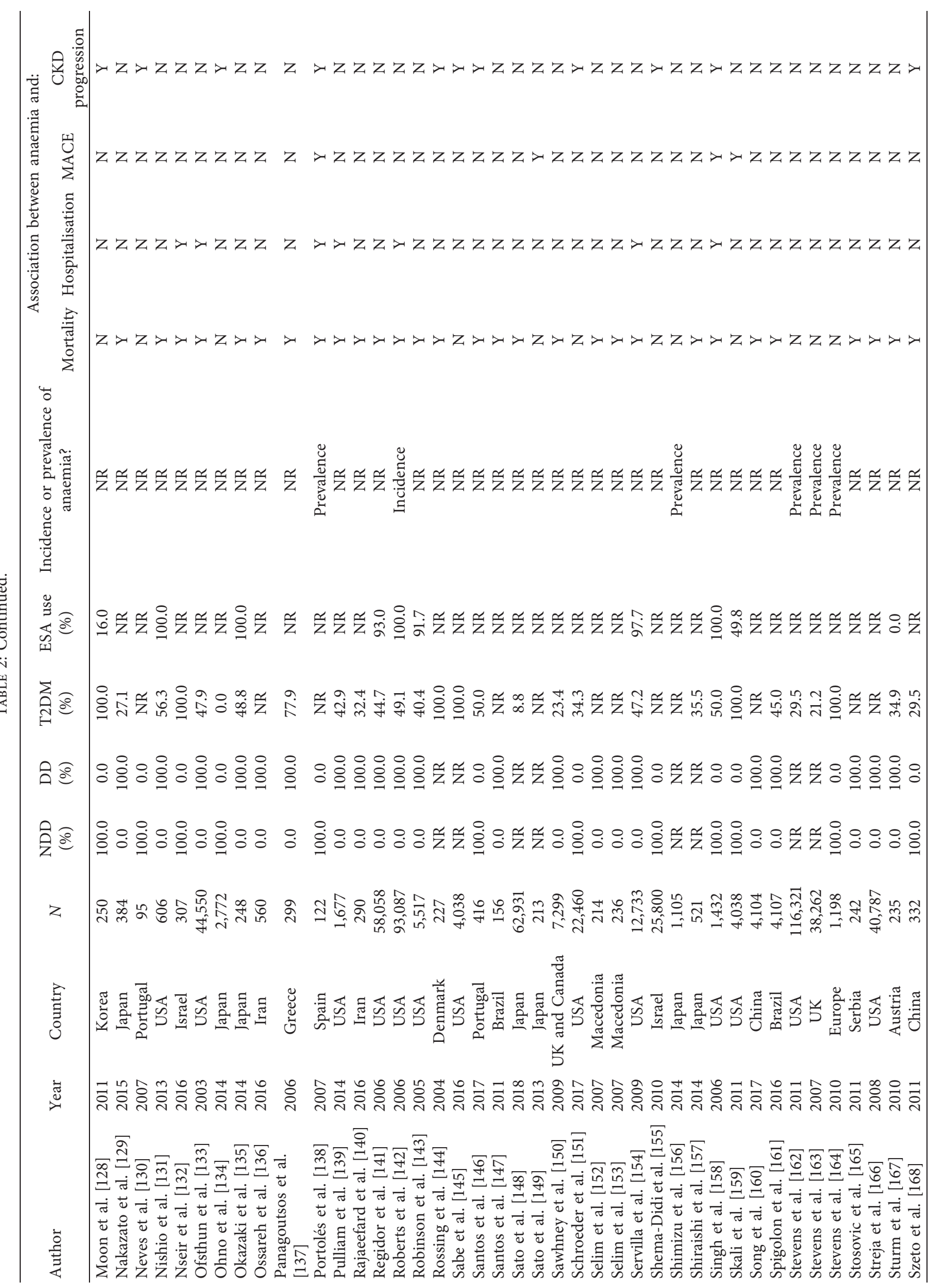




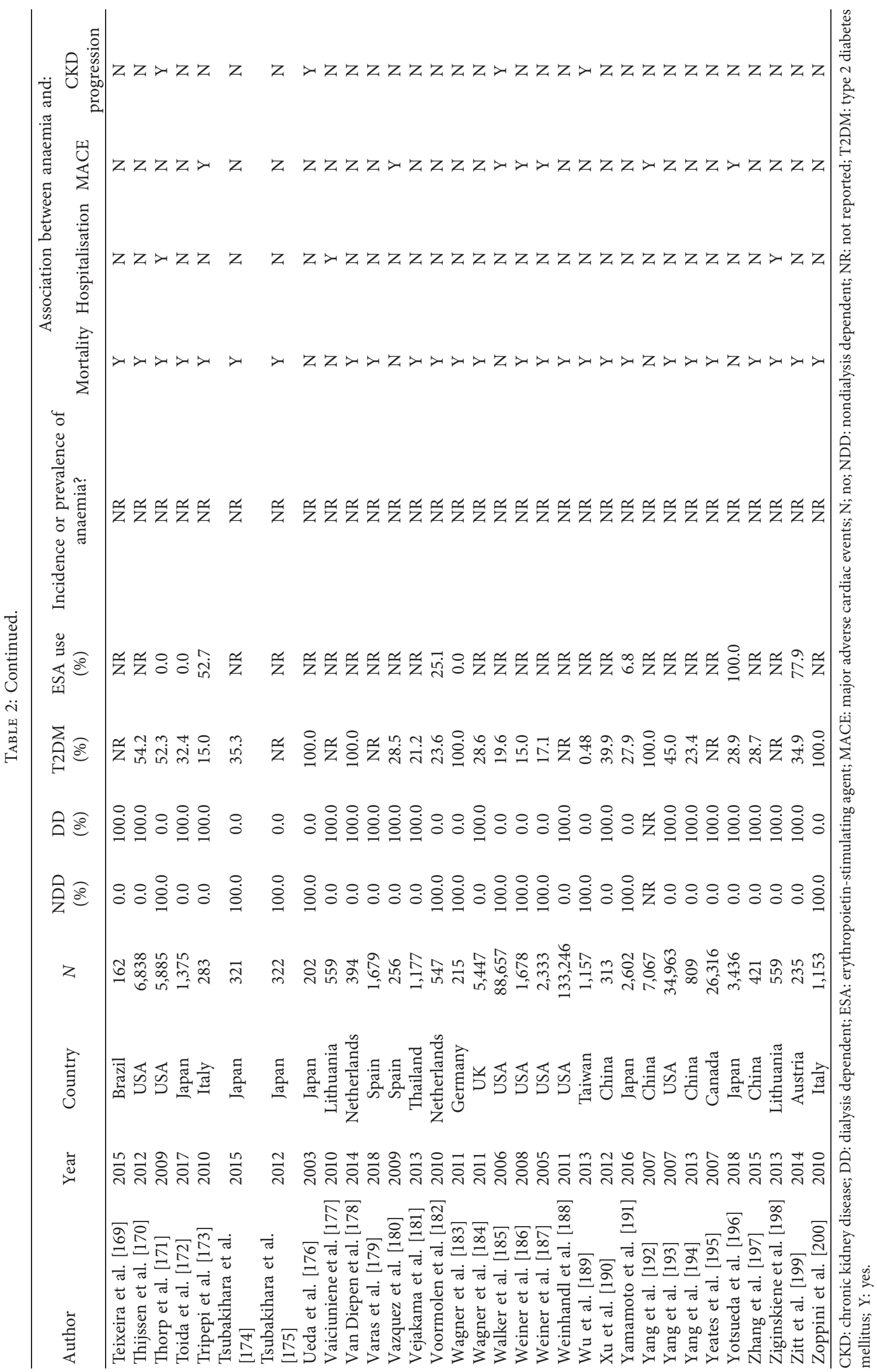




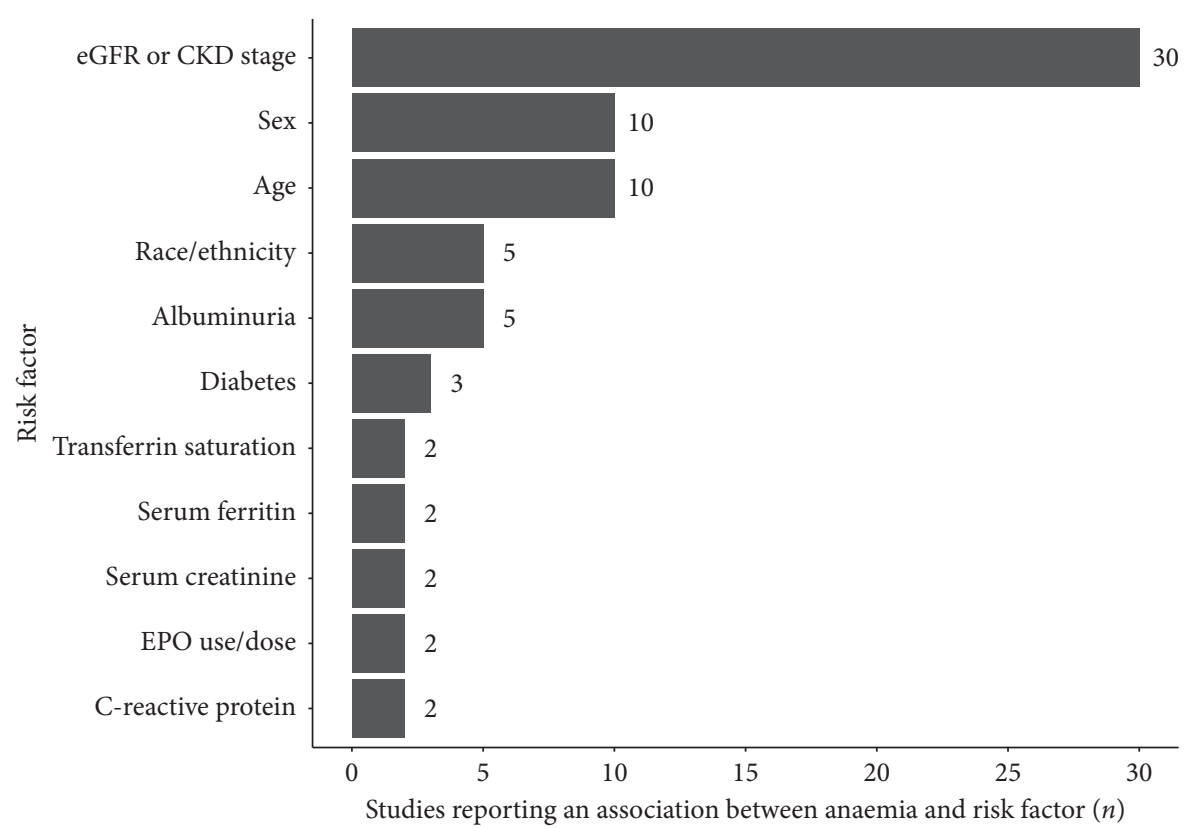

FIGURE 2: Risk factors associated with the presence of anaemia identified by more than one included study.

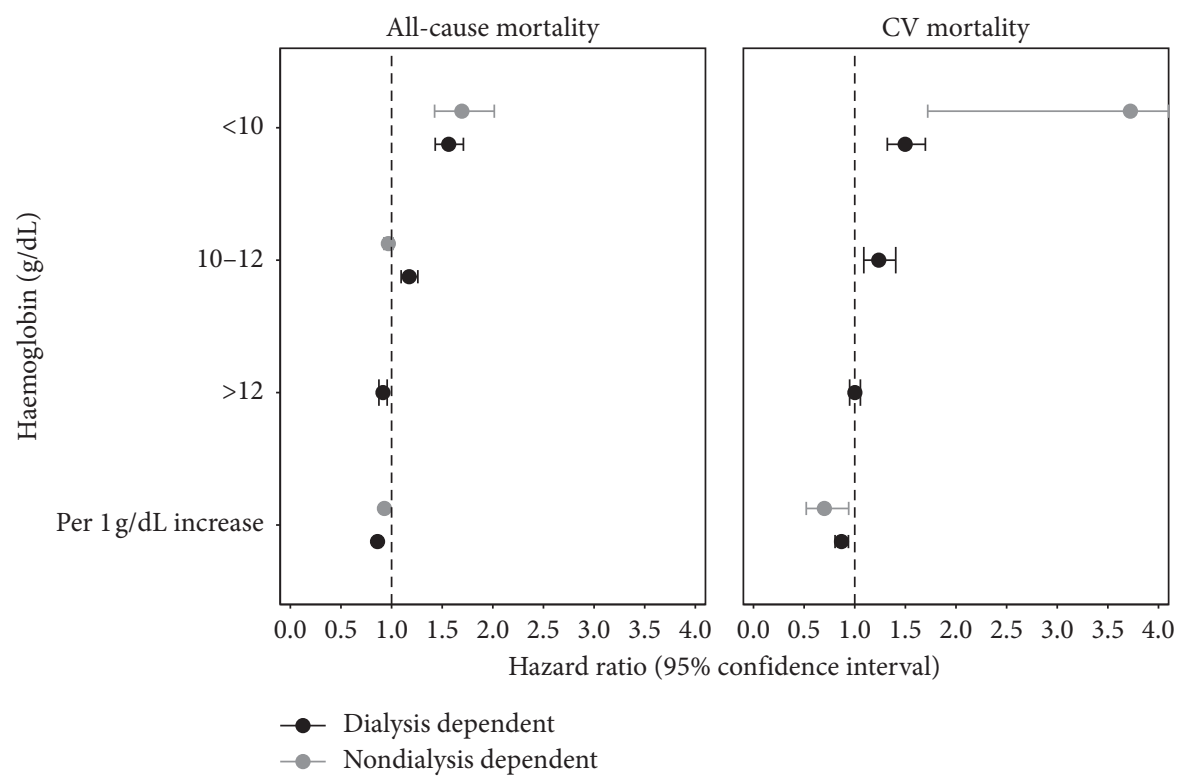

FIgURE 3: Associations between $\mathrm{Hb}$ level and mortality in CKD patients.

(1.07-1.11) and $0.91(0.87-0.96)$, respectively. No studies reported the risk of all-cause mortality in CKD patients not on dialysis with $\mathrm{Hb}$ of $10-12 \mathrm{~g} / \mathrm{dL}$ or $>12 \mathrm{~g} / \mathrm{dL}$.

The overall risk of hospitalisation when $\mathrm{Hb}$ concentration was reported as a continuous variable followed a similar pattern to the categorical data, of decreasing risk with increasing $\mathrm{Hb}$. The mean (95\% CI) HR for the risk of hospitalisation in dialysis patients $(n=4)$ was $0.92(0.87-0.98)$ per $1 \mathrm{~g} / \mathrm{dL}$ increase in $\mathrm{Hb}$. No studies reported the risk of hospitalisation in CKD patients not on dialysis where $\mathrm{Hb}$ was expressed as a continuous variable.
3.3.3. Association between Haemoglobin and Major Adverse Cardiac Events. An association between $\mathrm{Hb}$ concentration (or anaemia) and MACE was reported by 30 studies. Whilst some studies reported MACE specifically, others reported single components of MACE such as stroke, heart failure, and myocardial infarction; all MACE-type events were grouped for combined analysis in this SLR. 19 were studies conducted in CKD patient cohorts not on dialysis, seven studies in dialysis cohorts, and four studies that included both CKD patients not on dialysis and patients on dialysis. Mean HRs quantifying the risk of MACE based on $\mathrm{Hb}$ 


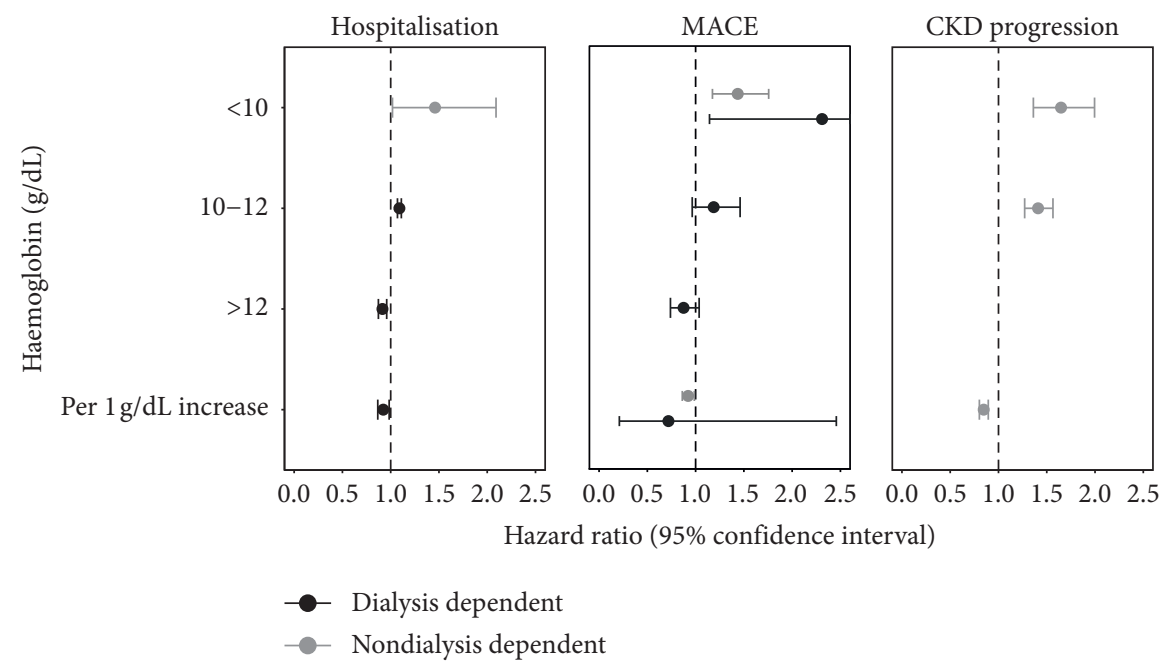

FIgURE 4: Associations between $\mathrm{Hb}$ level and hospitalisation, MACE, and CKD progression in CKD patients.

concentration are shown in Figure 4 (middle). The risks of MACE with anaemia tended to follow a similar pattern to the risks of mortality and hospitalisations, with higher levels of risk associated with lower $\mathrm{Hb}$ levels.

The mean $(95 \% \mathrm{CI}) \mathrm{HR}$ for the risk MACE in CKD patients not on dialysis with $\mathrm{Hb}<10 \mathrm{~g} / \mathrm{dL}(n=6)$ was 1.44 (1.17-1.76). The estimated HRs of MACE in patients on dialysis with $\mathrm{Hb}<10 \mathrm{~g} / \mathrm{dL}(n=1), 10-12 \mathrm{~g} / \mathrm{dL}(n=2)$, and $>12 \mathrm{~g} / \mathrm{dL}(n=1)$ were $2.31(1.14-4.66), 1.19(0.96-1.46)$, and 0.88 (0.74-1.04), respectively.

The overall risk of MACE in CKD patients when $\mathrm{Hb}$ concentration was expressed as a continuous variable followed a similar pattern to the categorical data, of decreasing risk with increasing $\mathrm{Hb}$. The mean $(95 \% \mathrm{CI}) \mathrm{HRs}$ for MACE in CKD patients not on dialysis $(n=5)$ and on dialysis $(n=2)$ were $0.92(0.86-0.99)$ and $0.72(0.21-2.46)$ per $1 \mathrm{~g} / \mathrm{dL}$ increase in $\mathrm{Hb}$, respectively.

\subsubsection{Association between Haemoglobin and CKD Progression.} An association between $\mathrm{Hb}$ or anaemia and CKD progression was reported by 38 studies. The majority $(n=28)$ defined CKD progression as progression to ESRD, with the remainder based on prespecified declines in eGFR or the doubling of serum creatinine. All studies were in cohorts of patients with CKD not on dialysis. Mean HRs quantifying the risk of CKD progression based on $\mathrm{Hb}$ levels are shown in Figure 4 (right).

The mean $(95 \% \mathrm{CI}) \mathrm{HRs}$ for the risk of CKD progression in CKD patients not on dialysis with $\mathrm{Hb}<10 \mathrm{~g} / \mathrm{dL}(n=11)$ and $10-12 \mathrm{~g} / \mathrm{dL}(n=1)$ were $1.65(1.36-2.00)$ and 1.41 (1.27-1.56), respectively.

The risk of CKD progression in CKD patients not on dialysis when $\mathrm{Hb}$ concentration was expressed as a continuous variable followed a similar pattern to the categorical data, of decreasing risk with increasing $\mathrm{Hb}$. The mean (95\% CI) HR for the risk of CKD progression in CKD patients not on dialysis $(n=18)$ was $0.85(0.80-0.89)$ per $1 \mathrm{~g} / \mathrm{dL}$ increase in $\mathrm{Hb}$.

\section{Discussion}

The aim of this review was to identify in a systematic manner the studies that reported risk factors associated with the presence of anaemia in patients with CKD and studies that characterised the association between anaemia ( $\mathrm{Hb}$ level) and outcomes in patients with CKD. In doing so, we have summarised a contemporary evidence base of the risks of anaemia in CKD patients. In total, 191 studies that reported risk factors associated with anaemia in CKD and/or associations between $\mathrm{Hb}$ and mortality, hospitalisation, MACE, and $\mathrm{CKD}$ progression were identified. Overall, more severe anaemia was consistently associated with a greater risk of adverse outcomes.

The incidence or prevalence of anaemia in patients with CKD was reported in 31 studies identified by this systematic review. Anaemia is relatively common in CKD patients especially with increasing disease severity, with rates of up to $90 \%$ in Stage 5 patients. Studies from the UK [201] and USA [202] reported overall prevalence rates of anaemia in CKD patients with diabetes of $22 \%$ and $15 \%$, ranging from $5 \%$ and $8 \%$ in Stage 1 up to $46 \%$ and 53\% in Stage 5, respectively. Higher overall prevalence rates (32\% and 52\%) have been reported in studies of Malaysian [203] and Chinese [204] patients, with prevalence ranging from $13 \%$ and $22 \%$ in Stage 1 up to $70 \%$ and $90 \%$ in Stage 5, respectively.

The most commonly reported risk factor for the development of anaemia was eGFR (or CKD stage). Data consistently indicated that more severe CKD was associated with greater prevalence of anaemia. There are a number of pathophysiological mechanisms responsible for the development of anaemia alongside CKD. Compared to patients with anaemia without CKD, diseased kidneys produce less EPO than would normally be expected relative to the degree of anaemia. Whether this insufficient EPO is due to an absolute reduction in production capacity or an impaired sensitivity of kidney cells to the low tissue oxygenation that would normally stimulate production is unknown $[205,206]$. More recent research has identified hepcidin as a 
key hormone implicated in disordered iron homeostasis in CKD patients. When elevated, hepcidin impairs dietary iron absorption and reduces the mobilisation of stored iron, further contributing to anaemia [207, 208]. Overall, anaemia in CKD is likely to be multifactorial and other factors such as shortened red blood cell survival, greater blood losses (especially in dialysis patients), and impaired absorption of dietary iron may further exacerbate the condition [4].

Older age and female sex were also commonly identified as a risk factors involved in the development of anaemia in patients with CKD. Older age is associated with greater inflammation and age-related comorbidities. The presence of proinflammatory cytokines (e.g., IL-6) increases hepcidin expression [209], likely placing older patients at higher risk of developing anaemia. Furthermore, sex hormone regulation is also impacted with older age, and both testosterone and oestrogen have been shown to reduce circulating hepcidin [210, 211]. Despite lower $\mathrm{Hb}$ thresholds for anaemia diagnosis in females $(<12 \mathrm{~g} / \mathrm{dL}$ vs. $<13 \mathrm{~g} / \mathrm{dL}$ for males), female patients with CKD tended to be at higher risk of developing anaemia than their male counterparts. Indeed, McClellan et al. [117] found that female patients with CKD were approximately two times more likely to develop anaemia than males. Race or ethnicity has also been identified as factors that affect the prevalence of anaemia in patients with CKD [212].

The majority of risk factors reported in the included studies were patient characteristics or comorbidities. Despite EPO and hepcidin playing a significant role in the development of anaemia in patients with CKD, only two studies identified in this SLR assessed the role of EPO as a risk factor for anaemia and no studies included hepcidin. Further work on these laboratory-based variables and their role in the risk of anaemia associated with varying levels of each biochemical parameter would be helpful to better understand the development of anaemia in patients with CKD.

Anaemia was associated with higher risks of all-cause mortality, CV mortality, MACE, hospitalisations, and CKD progression. The effects tended to increase with anaemia severity, such that a $\mathrm{Hb}<10 \mathrm{~g} / \mathrm{dL}$ was linked to comparable or higher risk of each outcome than a $\mathrm{Hb}$ of $10-12 \mathrm{~g} / \mathrm{dL}$. Although the effects tended to be consistent across CKD patients not on dialysis and those patients on dialysis in terms of direction, the magnitude of the risks of all-cause and $\mathrm{CV}$ mortality in patients with $\mathrm{CKD}$ not receiving dialysis appears to be greater than for those not on dialysis. The reason for this is unclear; however, due to small study numbers in some groups and an inability to control for other variables in the study populations, this finding should be interpreted with caution and may warrant further investigation. Nevertheless, the reasons for the association between anaemia and poorer outcomes are not well understood. Chronic anaemia is associated with increased cardiac output and reduced systemic vascular resistance. The low blood pressure resulting from systemic vasodilation may initiate a cascade of events, including increased sympathetic nervous activity and activation of the renin-angiotensin-aldosterone system to reduce salt and water excretion, thereby resulting in plasma volume expansion and oedema [213]. Overall, these changes result in greater cardiovascular workload, increasing the risk of conditions such as left ventricular hypertrophy $[214,215]$, and may contribute to the observation of higher rates of mortality, MACE, and hospitalisations observed with anaemia in CKD patients.

Anaemia is a common contributor to poor quality of life in patients with CKD but is also likely to be the factor that is most responsive to treatment [6]. Treatment of anaemia in CKD typically involves the use of supplemental iron (either oral or intravenous) and erythropoiesis-stimulating agents (ESAs) [205]. Supplemental iron may help improve iron status; however, it is not symptom- or risk-free and-depending on the mechanism(s) responsible for the anaemia-may not treat the condition adequately. ESAs mimic erythropoietin and act to stimulate red blood cell production in the bone marrow. However, although ESAs are successful at increasing haemoglobin levels in the majority of cases, they have not been shown to reduce the risks of adverse outcomes associated with anaemia in CKD patients [6] and may even result in increased risk of negative outcomes, as evidenced by three large randomised controlled trials [216-218].

The TREAT [218] study assessed the effect of darbepoetin alfa (ESA) versus placebo in more than 4000 patients with CKD, type 2 diabetes, and anaemia. HRs for death or CV event and for death or ESRD were similar; however, treatment group patients were almost two times more likely to suffer stroke (HR: 1.92 (95\% CI: 1.38-2.65); $p<0.001$ ) than control group patients. Additional studies have assessed the effect of ESA treatment based on different $\mathrm{Hb}$ target levels. The CREATE [217] trial assessed the effect of epoetin beta (ESA) administration on CV events in 603 patients with Stage 3 or $4 \mathrm{CKD}$ and mild-to-moderate anaemia ( $\mathrm{Hb}$ 11.0-12.5 g/dL). Patients were randomly assigned to receive ESA treatment to target a $\mathrm{Hb}$ level of $13.0-15.0 \mathrm{~g} / \mathrm{dL}$ or to only receive the ESA if their Hb dropped below $10.5 \mathrm{~g} / \mathrm{dL}$ (so as to maintain $\mathrm{Hb} 10.5-11.5 \mathrm{~g} / \mathrm{dL}$ ). ESA treatment successfully maintained $\mathrm{Hb}$ within predetermined ranges; however, treatment to normalise $\mathrm{Hb}$ (within $13.0-15.0 \mathrm{~g} / \mathrm{dL}$ ) was not associated with a reduction in the risk of CV events. Furthermore, the CHOIR [216] study involved the prescription of epoetin alfa (ESA) in 1400 patients with CKD to achieve a target $\mathrm{Hb}$ of either $13.5 \mathrm{~g} / \mathrm{dL}$ (high) or $11.3 \mathrm{~g} / \mathrm{dL}$ (low). Patients in the high $\mathrm{Hb}$ group experienced increased risk of composite (death, myocardial infarction, hospitalisation for congestive heart failure, or stroke) events (HR: 1.34 (95\% CI: 1.03-1.74); $p=0.03$ ) and no improvement in quality of life. Post hoc analyses from this study indicate that higher ESA doses (irrespective of $\mathrm{Hb}$ achieved) were the primary driver for the risk of adverse outcomes [219], indicating there is a need for more effective treatments.

Based on these trials, it is clear that high $\mathrm{Hb}$ targets should be avoided; however, it is unclear whether the poorer outcomes are due to the ESAs themselves or factors that often accompany low $\mathrm{Hb}$ such as inflammation, elevated hepcidin levels, blood loss, and/or malnutrition [4]. Ultimately, this uncertainty in trying to balance the risks of untreated anaemia against the risks of treatment with ESAs 
has led to frustration amongst many in the clinical community. With no clear effective intervention available to both restore $\mathrm{Hb}$ levels and improve outcomes, $\mathrm{Hb}$ remains little more than a biomarker for adverse outcomes in patients with CKD.

This study is not without limitations. There was wide heterogeneity-as evidenced by I-squared statistic - in the study design, study size, patient characteristics, treatments received, outcomes (e.g., coding systems of hospitalisations), and anaemia definitions. Such variations in reporting of variables and outcomes meant that large numbers of studies were either excluded or were unable to be included in the final analysis that summarised HRs for the risk of each outcome. Furthermore, when outcome data were subdivided by $\mathrm{Hb}$ category and by patients receiving dialysis or not, many gaps were apparent, preventing full understanding of the level of risk. A SLR is also limited by the data available in each individual study. Whilst the most adjusted (for demographics and comorbidities) measure of risk was preferentially extracted, not all studies performed this level of analysis which may affect the overall estimate of risk.

As with all SLRs, there is also the potential for publication bias to impact on the generalisability of results. Furthermore, geographical bias may also affect the generalisability of the findings. The majority of included studies were conducted in Asia, North America, and Europe, with small study numbers in other regions. Despite this, the findings were relatively consistent irrespective of geographical location, indicating the findings are relatively generalisable across different countries and different ethnic backgrounds. The majority of studies included in this review also only presented relative risks of adverse outcomes associated with $\mathrm{Hb}$ or anaemia, and in general, there is a lack of information regarding the absolute risks of outcomes in these patients which may present an avenue for future research. However, the number of identified studies and the size of the cohorts represented in this review allow the formulation of an overarching summary of the associated risks to patients with anaemia.

\section{Conclusion}

This is the first known systematic review to quantify the risks of mortality, hospitalisation, MACE, and CKD progression associated with anaemia severity in patients with CKD. Anaemia was associated with greater risk of all clinical outcomes, and the risk increased with anaemia severity. The burden of CKD and its complications is substantial and projected to increase. Effective treatments that not only treat the anaemia but also reduce the risk of adverse clinical outcomes are essential to help reduce the burden of anaemia and its management in CKD.

\section{Data Availability}

The data supporting this systematic review are from previously reported studies and datasets, which have been cited. The processed data are available from the corresponding author on reasonable request.

\section{Conflicts of Interest}

EP, SG, and $\mathrm{HvH}$ are employees of AstraZeneca. PM and OD are employed by a company providing research and dissemination services to AstraZeneca and other pharmaceutical companies.

\section{Acknowledgments}

Medical writing and editorial support was provided by Dr. Carissa Dickerson of Health Economics and Outcomes Research Ltd. This work was supported by AstraZeneca who provided support for the collection, analysis, and interpretation of data and the medical writing for this study.

\section{Supplementary Materials}

Table S1: MEDLINE search strategy. Table S2: EMBASE search strategy. Table S3: Cochrane Library search strategy. (Supplementary Materials)

\section{References}

[1] V. Jha, G. Garcia-Garcia, K. Iseki et al., "Chronic kidney disease: global dimension and perspectives," The Lancet, vol. 382, no. 9888, pp. 260-272, 2013.

[2] R. Thomas, A. Kanso, and J. R. Sedor, "Chronic kidney disease and its complications," Primary Care: Clinics in Office Practice, vol. 35, no. 2, pp. 329-344, 2008.

[3] WHO, Haemoglobin Concentrations for the Diagnosis of Anaemia and Assessment of Severity. Vitamin and Mineral Nutrition Information System, WHO, Geneva, Switzerland, 2011, https://www.who.int/vmnis/indicators/haemoglobin. pdf.

[4] J. L. Babitt and H. Y. Lin, "Mechanisms of anemia in CKD," Journal of the American Society of Nephrology, vol. 23, no. 10, pp. 1631-1634, 2012.

[5] J. Malyszko and M. Mysliwiec, "Hepcidin in anemia and inflammation in chronic kidney disease," Kidney and Blood Pressure Research, vol. 30, no. 1, pp. 15-30, 2007.

[6] KDOQI; National Kidney Foundation, "KDOQI clinical practice guidelines and clinical practice recommendations for anemia in chronic kidney disease," American Journal of Kidney Diseases, vol. 47, no. 5, pp. S11-S145, 2006.

[7] D. Moher, L. Shamseer, M. Clarke et al., "Preferred reporting items for systematic review and meta-analysis protocols (PRISMA-P) 2015 statement," Systematic Reviews, vol. 4, no. 1, p. 1, 2015.

[8] R Core Team, A Language and Environment for Statistical Computing, R Foundation for Statistical Computing, Vienna, Austria, 2014.

[9] S. Balduzzi, G. Rücker, and G. Schwarzer, "How to perform a meta-analysis with R: a practical tutorial," Evidence-Based Mental Health, vol. 22, no. 4, pp. 153-160, 2019.

[10] J. L. Abramson, C. T. Jurkovitz, Viola Vaccarino, W. S. Weintraub, and W. McClellan, "Chronic kidney disease, anemia, and incident stroke in a middle-aged, community-based population: the ARIC Study," Kidney International, vol. 64, no. 2, pp. 610-615, 2003.

[11] A. T. Ahmed, A. S. Go, E. M. Warton, M. M. Parker, and A. J. Karter, "Ethnic differences in anemia among patients with diabetes mellitus: the Diabetes Study of Northern 
California (DISTANCE)," American Journal of Hematology, vol. 85, no. 1, pp. 57-61, 2009.

[12] S. Y. Ahn, J. Ryu, S. H. Baek et al., "Incident chronic kidney disease and newly developed complications related to renal dysfunction in an elderly population during 5 years: a community-based elderly population cohort study," PLoS One, vol. 8, no. 12, Article ID e84467, 2013.

[13] T. Akizawa, R. L. Pisoni, T. Akiba et al., "Japanese haemodialysis anaemia management practices and outcomes (1999-2006): results from the DOPPS," Nephrology Dialysis Transplantation, vol. 23, no. 11, pp. 3643-3653, 2008.

[14] T. Akizawa, A. Saito, F. Gejyo et al., "Low hemoglobin levels and hypo-responsiveness to erythropoiesis-stimulating agent associated with poor survival in incident Japanese hemodialysis patients," Therapeutic Apheresis and Dialysis, vol. 18, no. 5, pp. 404-413, 2014.

[15] T. Akizawa, H. Hirakata, Y. Tsubakihara et al., "A prospective observational study of early intervention with erythropoietin therapy and renal survival in non-dialysis chronic kidney disease patients with anemia: jET-STREAM Study," Clinical and Experimental Nephrology, vol. 20, no. 6, pp. 885-895, 2016.

[16] M. Anees and M. Ibrahim, "Anemia and hypoalbuminemia at initiation of hemodialysis as risk factor for survival of dialysis patients," Journal of the College of Physicians and Surgeons Pakistan, vol. 19, no. 12, pp. 776-780, 2009.

[17] M. M. A. Anees, M. Ibrahim, S. M. Shaheen, and A. Asghar, "Effect of anemia and hyperhomocysteinemia on mortality of patients on hemodialysis," Iranian Journal of Kidney Diseases, vol. 4, no. 1, pp. 60-65, 2010.

[18] S. A. Antunes, M. E. F. Canziani, A. F. Campos, and R. Q. Vilela, "Hypoalbuminemia seems to be associated with a higher rate of hospitalization in hemodialysis patients," Jornal Brasileiro de Nefrologia, vol. 38, no. 1, pp. 70-75, 2016.

[19] S. Anutrakulchai, C. Pongskul, D. Sirivongs et al., "Factors associated with mortality and high treatment expense of adult patients hospitalized with chronic kidney disease in Thailand," Asian Biomedicine, vol. 10, no. 1, pp. 15-24, 2016.

[20] S. Arun, M. Venkatraya Prabhu, K. Nithyananda Chowta, and M. L. Bengre, "The haematological pattern of the patients with chronic kidney disease in a tertiary care setup in South India," Journal of Clinical and Diagnostic Research, vol. 6, no. 6, pp. 1003-1006, 2012.

[21] B. C. Astor, J. Coresh, G. Heiss, D. Pettitt, and M. J. Sarnak, "Kidney function and anemia as risk factors for coronary heart disease and mortality: the Atherosclerosis Risk in Communities (ARIC) study," American Heart Journal, vol. 151, no. 2, pp. 492-500, 2006.

[22] B. C. Astor, P. Muntner, A. Levin, J. A. Eustace, and J. Coresh, "Association of kidney function with anemia," Archives of Internal Medicine, vol. 162, no. 12, pp. 1401-1408, 2002.

[23] M. M. Avram, D. Blaustein, P. A. Fein, N. Goel, J. Chattopadhyay, and N. Mittman, "Hemoglobin predicts long-term survival in dialysis patients: a 15-year singlecenter longitudinal study and a correlation trend between prealbumin and hemoglobin," Kidney International, vol. 64, no. 87, pp. S6-S11, 2003.

[24] C. Babua, R. Kalyesubula, E. Okello et al., "Cardiovascular risk factors among patients with chronic kidney disease attending a tertiary hospital in Uganda," Cardiovascular Journal of Africa, vol. 26, no. 4, pp. 177-180, 2015.

[25] M. N. Bae, S. H. Kim, Y. O. Kim et al., "Association of erythropoietin-stimulating agent responsiveness with mortality in hemodialysis and peritoneal dialysis patients," PLoS One, vol. 10, no. 11, Article ID e0143348, 2015.

[26] C. B. Bowling, L. A. Inker, O. M. Gutiérrez et al., "Agespecific associations of reduced estimated glomerular filtration rate with concurrent chronic kidney disease complications," Clinical Journal of the American Society of Nephrology, vol. 6, no. 12, pp. 2822-2828, 2011.

[27] H. Beck, S. I. Titze, S. Hübner et al., "Heart failure in a cohort of patients with chronic kidney disease: the GCKD study," PLoS One, vol. 10, no. 6, Article ID e0131034, 2015.

[28] N. A. Bello, E. F. Lewis, A. S. Desai et al., "Increased risk of stroke with darbepoetin alfa in anaemic heart failure patients with diabetes and chronic kidney disease," European Journal of Heart Failure, vol. 17, no. 11, pp. 1201-1207, 2015.

[29] Y. Bentata, I. Haddiya, H. Latrech, K. Serraj, and R. Abouqal, "Progression of diabetic nephropathy, risk of end-stage renal disease and mortality in patients with type-1 diabetes," Saudi Journal of Kidney Diseases and Transplantation, vol. 24, no. 2, pp. 392-402, 2013.

[30] S. Bhatti, A. Hakeem, K. S. Dillie, J. R. Cook, and S. M. Chang, "Prevalence, prognosis, and therapeutic implications of unrecognized left ventricular systolic dysfunction in patients with anemia and chronic kidney disease," Congestive Heart Failure, vol. 16, no. 6, pp. 271-277, 2010.

[31] N. C. Boudville, O. Djurdjev, I. C. Macdougall et al., "Hemoglobin variability in nondialysis chronic kidney disease: examining the association with mortality," Clinical Journal of the American Society of Nephrology, vol. 4, no. 7, pp. 11761182, 2009.

[32] B. D. Bradbury, M. D. Danese, M. Gleeson, and C. W. Critchlow, "Effect of epoetin alfa dose changes on hemoglobin and mortality in hemodialysis patients with hemoglobin levels persistently below $11 \mathrm{~g} / \mathrm{dL}$," Clinical Journal of the American Society of Nephrology, vol. 4, no. 3, pp. 630-637, 2009.

[33] K. Bravo-Jaimes, A. Whittembury, and V. Santivanez, "High prevalence of cardiovascular disease in end-stage kidney disease patients ongoing hemodialysis in Peru: why should we care about it?" International Journal of Nephrology, vol. 2015, pp. 1-6, 2015.

[34] S. M. Brunelli, M. M. Joffe, R. K. Israni et al., "Historyadjusted marginal structural analysis of the association between hemoglobin variability and mortality among chronic hemodialysis patients," Clinical Journal of the American Society of Nephrology, vol. 3, no. 3, pp. 777-782, 2008.

[35] S. M. Brunelli, K. E. Lynch, E. D. Ankers et al., "Association of hemoglobin variability and mortality among contemporary incident hemodialysis patients," Clinical Journal of the American Society of Nephrology, vol. 3, no. 6, pp. 1733-1740, 2008.

[36] G. Buccianti, B. Baragetti, F. Bamonti, S. Furiani, V. Dorighet, and C. Patrosso, "Plasma homocysteine levels and cardiovascular mortality in patients with end-stage renal disease," Journal of Nephrology, vol. 17, no. 3, pp. 405-410, 2004.

[37] D. Cană-Ruiu, "Renal anemia-risk factor for chronic kidney disease," Current Health Sciences Journal, vol. 39, no. 4, pp. 214-217, 2013.

[38] J. P. Capelli and H. Kushner, "Correlates affecting survival in chronic hemodialysis patients: the combined impact of albumin and high hemoglobin levels on improving outcomes, local and national results," Hemodialysis International, vol. 12, no. 4, pp. 450-462, 2008. 
[39] K. E. Chan, J. M. Lazarus, R. L. Wingard, and R. M. Hakim, "Association between repeat hospitalization and early intervention in dialysis patients following hospital discharge," Kidney International, vol. 76, no. 3, pp. 331-341, 2009.

[40] L. Chan, K. Chauhan, P. Poojary et al., "National estimates of 30-day unplanned readmissions of patients on maintenance hemodialysis," Clinical Journal of the American Society of Nephrology, vol. 12, no. 10, pp. 1652-1662, 2017.

[41] P. Y. Chang, L.-N. Chien, Y. F. Lin, M. S. Wu, W. T. Chiu, and H. Y. Chiou, "Risk factors of gender for renal progression in patients with early chronic kidney disease," Medicine, vol. 95, no. 30, 2016.

[42] C. X. R. Chen, Y. C. Li, S. L. Chan, and K. H. Chan, “Anaemia and type 2 diabetes: implications from a retrospectively studied primary care case series," Hong Kong Medical Journal, vol. 19, no. 3, pp. 214-221, 2013.

[43] S. C. Chen, H.-M. Su, Y. C. Tsai et al., "Framingham risk score with cardiovascular events in chronic kidney disease," PLoS One, vol. 8, no. 3, Article ID e60008, 2013.

[44] S.-C. Chen, J.-M. Chang, W.-C. Liu et al., "The ratio of observed to predicted left ventricular mass is independently associated with increased cardiovascular events in patients with chronic kidney disease," Hypertension Research, vol. 35, no. 8, pp. 832-838, 2012.

[45] X. Chen, B. Shen, J. Zou et al., "The prognostic value of red blood cell distribution width in patients on maintenance hemodialysis," Blood Purification, vol. 42, no. 4, pp. 314-321, 2016.

[46] N. Chen, X.-X. Pan, Y. Gu et al., "Analysis of early kidney damage in hospitalized patients with chronic kidney disease: a multicenter study," Renal Failure, vol. 34, no. 3, pp. 329333, 2012.

[47] M. Chonchol, G. Lippi, M. Montagnana, M. Muggeo, and G. Targher, "Association of inflammation with anaemia in patients with chronic kidney disease not requiring chronic dialysis," Nephrology Dialysis Transplantation, vol. 23, no. 9, pp. 2879-2883, 2008.

[48] A. J. Christensen, S. L. Ehlers, J. S. Wiebe et al., "Patient personality and mortality: a 4-year prospective examination of chronic renal insufficiency," Health Psychology, vol. 21, no. 4, pp. 315-320, 2002.

[49] B. Conway, L. Fried, and T. Orchard, "Hemoglobin and overt nephropathy complications in type 1 diabetes," Annals of Epidemiology, vol. 18, no. 2, pp. 147-155, 2008.

[50] L. de Nicola, P. Chiodini, C. Zoccali et al., "Prognosis of CKD patients receiving outpatient nephrology care in Italy," Clinical Journal of the American Society of Nephrology, vol. 6, no. 10, pp. 2421-2428, 2011.

[51] L. De Nicola, P. Chiodini, R. Minutolo et al., "The effect of increasing age on the prognosis of non-dialysis patients with chronic kidney disease receiving stable nephrology care," Kidney International, vol. 82, no. 4, pp. 482-488, 2012.

[52] L. De Nicola, R. Minutolo, P. Chiodini et al., "Prevalence and prognosis of mild anemia in non-dialysis chronic kidney disease: a prospective cohort study in outpatient renal clinics," American Journal of Nephrology, vol. 32, no. 6, pp. 533-540, 2010.

[53] L. De Nicola, M. Provenzano, P. Chiodini et al., "Epidemiology of low-proteinuric chronic kidney disease in renal clinics," PLoS One, vol. 12, no. 2, Article ID e0172241, 2017.

[54] A. S. Desai, R. Toto, P. Jarolim et al., "Association between cardiac biomarkers and the development of ESRD in patients with type 2 diabetes mellitus, anemia, and CKD," American Journal of Kidney Diseases, vol. 58, no. 5, pp. 717-728, 2011.
[55] L. Djukanović, N. Dimković, J. Marinković et al., "Compliance with guidelines and predictors of mortality in hemodialysis. Learning from Serbia patients," Nefrologia, vol. 35, no. 3, pp. 287-295, 2015.

[56] O. Dmitrieva, S. de Lusignan, I. C. Macdougall et al., "Association of anaemia in primary care patients with chronic kidney disease: cross sectional study of quality improvement in chronic kidney disease (QICKD) trial data," $\mathrm{BMC} \mathrm{Ne}$ phrology, vol. 14, no. 24, 2013.

[57] P. E. Drawz, D. C. Babineau, and M. Rahman, "Metabolic complications in elderly adults with chronic kidney disease," Journal of the American Geriatrics Society, vol. 60, no. 2, pp. 310-315, 2012.

[58] D. Du Cheyron, J.-J. Parienti, M. Fekih-Hassen, C. Daubin, and P. Charbonneau, "Impact of anemia on outcome in critically ill patients with severe acute renal failure," Intensive Care Medicine, vol. 31, no. 11, pp. 1529-1536, 2005.

[59] B. Faller, J.-B. Beuscart, and L. Frimat, "Competing-risk analysis of death and dialysis initiation among elderly $(\geq 80$ years) newly referred to nephrologists: a French prospective study," BMC Nephrology, vol. 14, no. 1, 2013.

[60] M. H. Fathelrahman, "Anemia in Sudanese Patients with Chronic Renal Failure (CRF) and in Patients undergoing Chronic Hemodialysis," Bangladesh Journal of Medical Science, vol. 11, no. 1, pp. 44-50, 2012.

[61] H. I. Feldman, B. Robinson, J. Knauss et al., "Administration of parenteral iron and mortality among hemodialysis patients," Journal of the American Society of Nephrology, vol. 15, no. 6, pp. 1623-1632, 2004.

[62] H. I. Feldman, J. Santanna, W. Guo et al., "Iron administration and clinical outcomes in hemodialysis patients," Journal of the American Society of Nephrology, vol. 13, no. 3, pp. 734-44, 2002.

[63] P. Ferrari, J. Xiao, A. Ukich, and A. Irish, "Estimation of glomerular filtration rate: does haemoglobin discriminate between ageing and true CKD?" Nephrology Dialysis Transplantation, vol. 24, no. 6, pp. 1828-1833, 2009.

[64] J. Fort, X. Cuevas, F. Garcia et al., "Mortality in incident haemodialysis patients: time-dependent haemoglobin levels and erythropoiesis-stimulating agent dose are independent predictive factors in the ANSWER study," Nephrology Dialysis Transplantation, vol. 25, no. 8, pp. 2702-2710, 2010.

[65] D. L. Frankenfield, S. H. Roman, and W. M. McClellan, "Survival advantage for adult hispanic hemodialysis patients? Findings from the end-stage renal disease clinical performance measures project," Journal of the American Society of Nephrology, vol. 14, no. 1, pp. 180-186, 2003.

[66] R. P. Fraser SDS, C. R. May, N. McIntyre et al., "The burden of Comorbidity in people with chronic kidney disease stage 3: a cohort study," BMC Nephrology, vol. 16, no. 1, 2015.

[67] S. Fukuma, T. Yamaguchi, S. Hashimoto et al., "Erythropoiesis-stimulating agent responsiveness and mortality in hemodialysis patients: results from a cohort study from the dialysis registry in Japan," American Journal of Kidney Diseases, vol. 59, no. 1, pp. 108-116, 2012.

[68] K. Garlo, D. Williams, L. Lucas et al., "Severity of anemia predicts hospital length of stay but not readmission in patients with chronic kidney disease," Medicine, vol. 94, no. 25, p. e964, 2015.

[69] A. S. Go, J. Yang, T. C. Tan et al., "Contemporary rates and predictors of fast progression of chronic kidney disease in adults with and without diabetes mellitus," BMC Nephrology, vol. 19, no. 1, 2018. 
[70] M. Goicoechea, S. Garciéa de Vinuesa, F. Gómez-Campderá et al., "Clinical significance of cardiac troponin $\mathrm{T}$ levels in chronic kidney disease patients: predictive value for cardiovascular risk," American Journal of Kidney Diseases, vol. 43, no. 5, pp. 846-853, 2004.

[71] J.-C. Guan, W. Bian, X.-H. Zhang, Z.-F. Shou, and J.-H. Chen, "Influence of peritoneal transport characteristics on nutritional status and clinical outcome in Chinese diabetic nephropathy patients on peritoneal dialysis," Chinese Medical Journal, vol. 128, no. 7, pp. 859-864, 2015.

[72] S. Y. Han, S. W. Oh, J. W. Hong et al., "Association of estimated glomerular filtration rate with hemoglobin level in Korean adults: the 2010-2012 Korea national Health and nutrition examination survey," PLoS One, vol. 11, no. 4, Article ID e0150029, 2016.

[73] N. Hanafusa, T. Nomura, T. Hasegawa, and M. Nangaku, "Age and anemia management: relationship of hemoglobin levels with mortality might differ between elderly and nonelderly hemodialysis patients," Nephrology Dialysis Transplantation, vol. 29, no. 12, pp. 2316-2326, 2014.

[74] T. Hasegawa, S. K. Sakamaki, F. Koiwa et al., "Clinical prediction models for progression of chronic kidney disease to end-stage kidney failure under pre-dialysis nephrology care: results from the Chronic Kidney Disease Japan Cohort Study," Clinical and Experimental Nephrology, vol. 23, no. 2, pp. 189-198, 2019.

[75] T. Hayashi, T. Kimura, K. Yasuda et al., "Prognostic significance of left ventricular hypertrophy observed at dialysis initiation depends on the pre-dialysis use of erythropoiesisstimulating agents," Clinical and Experimental Nephrology, vol. 17, no. 2, pp. 294-303, 2013.

[76] J. He, M. Shlipak, A. Anderson et al., "Risk factors for heart failure in patients with chronic kidney disease: the CRIC (Chronic Renal Insufficiency Cohort) study," Journal of the American Heart Association, vol. 6, no. 5, 2017.

[77] C. A. Herzog, H. A. Muster, S. Li, and A. J. Collins, "Impact of congestive heart failure, chronic kidney disease, and anemia on survival in the Medicare population," Journal of Cardiac Failure, vol. 10, no. 6, pp. 467-472, 2004.

[78] M. S. Hosseini, Z. Rostami, A. Saadat, S. M. Saadatmand, and E. Naeimi, "Anemia and microvascular complications in patients with type 2 diabetes mellitus," Nephro-Urology Monthly, vol. 6, no. 4, 2014.

[79] S. C. Hung, K. L. Kuo, C. H. Peng, C. H. Wu, Y. C. Wang, and D. C. Tarng, "Association of fluid retention with anemia and clinical outcomes among patients with chronic kidney disease," Journal of the American Heart Association, vol. 4, no. 1, 2015.

[80] S. Iimori, S. Naito, Y. Noda et al., "Anaemia management and mortality risk in newly visiting patients with chronic kidney disease in Japan: the CKD-ROUTE study," $\mathrm{Ne}$ phrology, vol. 20, no. 9, pp. 601-608, 2015.

[81] G. Imamović, R. Hrvačević, S. Kapun et al., "Survival of incident patients on high-volume online hemodiafiltration compared to low-volume online hemodiafiltration and highflux hemodialysis," International Urology and Nephrology, vol. 46, no. 6, pp. 1191-1200, 2014.

[82] L. A. Inker, J. Coresh, A. S. Levey, M. Tonelli, and P. Muntner, "Estimated GFR, albuminuria, and complications of chronic kidney disease," Journal of the American Society of Nephrology, vol. 22, no. 12, pp. 2322-2331, 2011.

[83] J. K. Inrig, H. X. Barnhart, D. Reddan et al., "Effect of hemoglobin target on progression of kidney disease: a secondary analysis of the CHOIR (Correction of Hemoglobin and Outcomes in Renal Insufficiency) trial," American Journal of Kidney Diseases, vol. 60, no. 3, pp. 390-401, 2012.

[84] E. Isakov, P. Froom, C. Henig, and M. Barak, "Anemia and estimated glomerular filtration rates," Annals of Clinical and Laboratory Science, vol. 44, no. 4, pp. 419-424, 2014.

[85] J. Ishigami, T. Onishi, S. Shikuma et al., "The impact of hyporesponsiveness to erythropoietin-stimulating agents on time-dependent mortality risk among CKD stage $5 \mathrm{D}$ patients: a single-center cohort study," Clinical and Experimental Nephrology, vol. 17, no. 1, pp. 106-114, 2013.

[86] J. Ishigami, M. E. Grams, R. P. Naik et al., "Hemoglobin, albuminuria, and kidney function in cardiovascular risk: the ARIC (atherosclerosis risk in communities) study," Journal of the American Heart Association, vol. 7, no. 2, 2018.

[87] S. Ito, S. Murai, M. Sugiura, T. Yoshida, and T. Fukutomi, "Predictors of congestive heart failure in patients on maintenance hemodialysis," Circulation Journal, vol. 71, no. 9, pp. 1424-1429, 2007.

[88] E. S. Johnson, M. L. Thorp, X. Yang, O. L. Charansonney, and D. H. Smith, "Predicting renal replacement therapy and mortality in CKD," American Journal of Kidney Diseases, vol. 50, no. 4, pp. 559-565, 2007.

[89] E. S. Johnson, M. L. Thorp, R. W. Platt, and D. H. Smith, "Predicting the risk of dialysis and transplant among patients with CKD: a retrospective cohort study," American Journal of Kidney Diseases, vol. 52, no. 4, pp. 653-660, 2008.

[90] U. Joshi, Q. Guo, C. Yi et al., "Clinical outcome in elderly patients on chronic peritoneal dialysis: a retrospective study from a single center in China," Peritoneal Dialysis International: Journal of the International Society for Peritoneal Dialysis, vol. 34, no. 3, pp. 299-307, 2014.

[91] N. Joss, R. Patel, K. Paterson, K. Simpson, C. Perry, and C. Stirling, "Anaemia is common and predicts mortality in diabetic nephropathy," QJM, vol. 100, no. 10, pp. 641-647, 2007.

[92] M. Y. Jung, S. Y. Hwang, Y. A. Hong et al., "Optimal hemoglobin level for anemia treatment in a cohort of hemodialysis patients," Kidney Research and Clinical Practice, vol. 34, no. 1, pp. 20-27, 2015.

[93] H. Kataoka, K. Tsuchiya, T. Naganuma et al., "Relationship between anaemia management at haemodialysis initiation and patient prognosis," Nephrology, vol. 20, pp. 14-21, 2015.

[94] W. F. Keane, B. M. Brenner, D. de Zeeuw et al., "The risk of developing end-stage renal disease in patients with type 2 diabetes and nephropathy: the RENAAL study," Kidney International, vol. 63, no. 4, pp. 1499-1507, 2003.

[95] W. F. Keane, Z. Zhang, P. A. Lyle et al., "Risk scores for predicting outcomes in patients with type 2 diabetes and nephropathy: the RENAAL study," Clinical Journal of the American Society of Nephrology, vol. 1, no. 4, pp. 761-767, 2006.

[96] T. M. Keough-Ryan, B. A. Kiberd, C. S. Dipchand et al., "Outcomes of acute coronary syndrome in a large Canadian cohort: impact of chronic renal insufficiency, cardiac interventions, and anemia," American Journal of Kidney Diseases, vol. 46, no. 5, pp. 845-855, 2005.

[97] Y. H. Khan, A. Sarriff, A. S. Adnan, A. H. Khan, T. H. Mallhi, and F. Jummaat, "Progression and outcomes of non-dialysis dependent chronic kidney disease patients: a single center longitudinal follow-up study," Nephrology, vol. 22, no. 1, pp. 25-34, 2017.

[98] C. P. Kovesdy, B. K. Trivedi, and J. E. Anderson, "Association of kidney function with mortality in patients with chronic kidney disease not yet on dialysis: a historical prospective 
cohort study," Advances in Chronic Kidney Disease, vol. 13, no. 2, pp. 183-188, 2006.

[99] C. P. Kovesdy, B. K. Trivedi, K. Kalantar-Zadeh, and J. E. Anderson, "Association of anemia with outcomes in men with moderate and severe chronic kidney disease," Kidney International, vol. 69, no. 3, pp. 560-564, 2006.

[100] C. P. Kovesdy, B. K. Trivedi, K. Kalantar-Zadeh, and J. E. Anderson, "Association of low blood pressure with increased mortality in patients with moderate to severe chronic kidney disease," Nephrology Dialysis Transplantation, vol. 21, no. 5, pp. 1257-1262, 2006.

[101] I. C. Kuo, Y.-H. Hugo, S. W. Niu et al., "Anemia modifies the prognostic value of glycated hemoglobin in patients with diabetic chronic kidney disease," PLoS One, vol. 13, no. 6, Article ID e0199378, 2018.

[102] K. L. Kuo, S.-C. Hung, W. C. Tseng et al., "Association of anemia and iron parameters with mortality among patients undergoing prevalent hemodialysis in Taiwan: the AIM-HD study," Journal of the American Heart Association, vol. 7, no. 15, 2018.

[103] M. Kuwahara, S. Mandai, Y. Kasagi et al., "Responsiveness to erythropoiesis-stimulating agents and renal survival in patients with chronic kidney disease," Clinical and Experimental Nephrology, vol. 19, no. 4, pp. 598-605, 2015.

[104] O. Kwon, H. M. Jang, H. Y. Jung et al., "The Korean clinical research center for end- stage renal disease study validates the association of hemoglobin and erythropoiesis-stimulating agent dose with mortality in hemodialysis patients," PLoS One, vol. 10, no. 10, Article ID e0140241, 2015.

[105] E. Lacson Jr, W. Wang, R. M. Hakim, M. Teng, and J. M. Lazarus, "Associates of mortality and hospitalization in hemodialysis: potentially actionable laboratory variables and vascular access," American Journal of Kidney Diseases, vol. 53, no. 1, pp. 79-90, 2009.

[106] F. Lattanzio, A. Corsonello, A. Montesanto et al., "Disentangling the impact of chronic kidney disease, anemia, and mobility limitation on mortality in older patients discharged from hospital," The Journals of Gerontology Series A: Biological Sciences and Medical Sciences, vol. 70, no. 9, pp. 1120-1127, 2015.

[107] B. C. V. Lau, K. Y. Ong, C. W. Yap, A. Vathsala, and P. How, "Predictors of anemia in a multi-ethnic chronic kidney disease population: a case-control study," SpringerPlus, vol. 4, no. 1, p. 233, 2015.

[108] A. Levin, O. Djurdjev, M. Beaulieu, and L. Er, "Variability and risk factors for kidney disease progression and death following attainment of stage $4 \mathrm{CKD}$ in a referred cohort," American Journal of Kidney Diseases, vol. 52, no. 4, pp. 661-671, 2008.

[109] A. Levin, O. Djurdjev, J. Duncan, D. Rosenbaum, and R. Werb, "Haemoglobin at time of referral prior to dialysis predicts survival: an association of haemoglobin with longterm outcomes," Nephrology Dialysis Transplantation, vol. 21, no. 2, pp. 370-377, 2006.

[110] M. F.G. Li Vecchi, M. Francesco, D. Mancuso et al., "Prevalence and severity of anaemia in patients with type 2 diabetic nephropathy and different degrees of chronic renal insufficiency," Nephron-Clinical Practice, vol. 105, no. 2, pp. c62-c67, 2007.

[111] C. L. Lin, F. R. Chuang, C. F. Wu, and C. T. Yang, "Early referral as an independent predictor of clinical outcome in end-stage renal disease on hemodialysis and continuous ambulatory peritoneal dialysis," Renal Failure, vol. 26, no. 5, pp. 531-537, 2004.
[112] T.-C. Lin, M.-T. Kao, M.-N. Lai, and C.-C. Huang, "Mortality difference by dialysis modality among new ESRD patients with and without diabetes mellitus," Dialysis \& Transplantation, vol. 35, no. 4, pp. 234-244, 2006.

[113] C.-H. Lin, Y.-F. Tu, W.-C. Chiang, S.-Y. Wu, Y.-H. Chang, and C.-H. Chi, "Electrolyte abnormalities and laboratory findings in patients with out-of-hospital cardiac arrest who have kidney disease," The American Journal of Emergency Medicine, vol. 31, no. 3, pp. 487-493, 2013.

[114] X. Liu, H. Wu, J. Wu et al., "Patient characteristics and risk factors of early and late death in incident peritoneal dialysis patients," Scientific Reports, vol. 6, Article ID 32359, 2016.

[115] F. Locatelli, R. L. Pisoni, C. Combe et al., "Anaemia in haemodialysis patients of five European countries: association with morbidity and mortality in the Dialysis Outcomes and Practice Patterns Study (DOPPS)," Nephrology Dialysis Transplantation, vol. 19, no. 1, pp. 121-132, 2004.

[116] I. C. Macdougall, C. R. V. Tomson, M. Steenkamp, and D. Ansell, "Relative risk of death in UK haemodialysis patients in relation to achieved haemoglobin from 1999 to 2005: an observational study using UK renal registry data incorporating 30,040 patient-years of follow-up," Nephrology Dialysis Transplantation, vol. 25, no. 3, pp. 914-919, 2010.

[117] W. McClellan, S. L. Aronoff, W. K. Bolton et al., "The prevalence of anemia in patients with chronic kidney disease," Current Medical Research and Opinion, vol. 20, no. 9, pp. 1501-1510, 2004.

[118] P. A. McCullough, P. E. Pergola, J. B. McGill et al., "Independent components of chronic kidney disease as a cardiovascular risk state," Archives of Internal Medicine, vol. 167, no. 11, pp. 1122-1129, 2007.

[119] L. P. McMahon, M. X Cai, S. Baweja et al., "Mortality in dialysis patients may not be associated with ESA dose: a 2year prospective observational study," BMC Nephrology, vol. 13, no. 1, 2012.

[120] P. Messa, M. Cozzolino, D. Brancaccio et al., "Effect of VDRA on survival in incident hemodialysis patients: results of the FARO-2 observational study," BMC Nephrology, vol. 16, no. 1, 2015.

[121] W. Metcalfe, I. H. Khan, G. J. Prescott et al., "End-stage renal disease in Scotland: outcomes and standards of care," Kidney International, vol. 64, no. 5, pp. 1808-1816, 2003.

[122] R. Minutolo, P. Chiodini, B. Cianciaruso et al., "Epoetin therapy and hemoglobin level variability in nondialysis patients with chronic kidney disease," Clinical Journal of the American Society of Nephrology, vol. 4, no. 3, pp. 552-559, 2009.

[123] R. Minutolo, G. Conte, B. Cianciaruso et al., "Hyporesponsiveness to erythropoiesis-stimulating agents and renal survival in non-dialysis CKD patients," Nephrology Dialysis Transplantation, vol. 27, no. 7, pp. 2880-2886, 2012.

[124] R. Minutolo, F. Lapi, P. Chiodini et al., "Risk of ESRD and death in patients with CKD not referred to a nephrologist: A 7 -year prospective study," Clinical Journal of the American Society of Nephrology, vol. 9, no. 9, pp. 1586-1593, 2014.

[125] A. Mohanram, Z. Zhang, S. Shahinfar, W. F. Keane, B. M. Brenner, and R. D. Toto, "Anemia and end-stage renal disease in patients with type 2 diabetes and nephropathy," Kidney International, vol. 66, no. 3, pp. 1131-1138, 2004.

[126] V. M. Mokoli, E. K. Sumaili, F. B. Lepira et al., "Impact of residual urine volume decline on the survival of chronic hemodialysispatients in Kinshasa," BMC Nephrology, vol. 17, no. 1, 2016. 
[127] M. Z. Molnar, R. Mehrotra, U. Duong, C. P. Kovesdy, and K. Kalantar-Zadeh, "Association of hemoglobin and survival in peritoneal dialysis patients," Clinical Journal of the American Society of Nephrology, vol. 6, no. 8, pp. 1973-1981, 2011.

[128] S. J. Moon, K. S. Bae, H. C. Park et al., "The effect of anemia and left ventricular geometric patterns on renal disease progression in type 2 diabetic nephropathy," Journal of Nephrology, vol. 24, no. 1, pp. 50-59, 2011.

[129] Y. Nakazato, R. Kurane, S. Hirose, A. Watanabe, and H. Shimoyama, "Variability of laboratory parameters is associated with frailty markers and predicts non-cardiac mortality in hemodialysis patients," Clinical and Experimental Nephrology, vol. 19, no. 6, pp. 1165-1178, 2015.

[130] P. L. Neves, E. Morgado, A. Baptista et al., "Anemia and interleukin-6 are associated with faster progression to endstage renal disease," Dialysis \& Transplantation, vol. 36, no. 8, pp. 445-456, 2007.

[131] A. Nishio, B. P. Chhatkuli, J. Z. Ma, and K. Kalantari, "Higher doses of erythropoietin-stimulating agents and hyporesponsiveness to their effects are associated with increased mortality among prevalent hemodialysis patients," Blood Purification, vol. 36, no. 1, pp. 29-36, 2013.

[132] W. Nseir, S. Artul, N. Nasrallah, J. Mograbi, and M. Mahamid, "Hospitalization and 1-year all-cause mortality in type 2 diabetic patients with chronic kidney disease at stages 1 and 2: effect of mild anemia," Journal of Diabetes, vol. 8, no. 4, pp. 502-507, 2016.

[133] N. Ofsthun, J. Labrecque, E. Lacson, M. Keen, and J. M. Lazarus, "The effects of higher hemoglobin levels on mortality and hospitalization in hemodialysis patients," Kidney International, vol. 63, no. 5, pp. 1908-1914, 2003.

[134] M. Ohno, F. Deguchi, K. Izumi et al., "Correlation between renal function and common risk factors for chronic kidney disease in a healthy middle-aged population: a prospective observational 2-year study," PLoS One, vol. 9, no. 11, Article ID e113263, 2014.

[135] M. Okazaki, M. Komatsu, H. Kawaguchi, K. Tsuchiya, and K. Nitta, "Erythropoietin resistance index and the all-cause mortality of chronic hemodialysis patients," Blood Purification, vol. 37, no. 2, pp. 106-112, 2014.

[136] S. Ossareh, F. Farrokhi, and M. Zebarjadi, "Survival of patients on hemodialysis and predictors of mortality: a singlecentre analysis of time-dependent factors," Iranian Journal of Kidney Diseases, vol. 10, no. 6, pp. 369-380, 2016.

[137] S. Panagoutsos, K. Kantartzi, P. Passadakis et al., "Timely transfer of peritoneal dialysis patients to hemodialysis improves survival rates," Clinical Nephrology, vol. 65, no. 1, pp. 43-47, 2006.

[138] J. Portolés, J. M. Lopez-Gomez, and P. Aljama, "A prospective multicentre study of the role of anaemia as a risk factor in haemodialysis patients: the MAR study," Nephrology Dialysis Transplantation, vol. 22, no. 2, pp. 500-507, 2006.

[139] J. Pulliam, N.-C. Li, F. Maddux, R. Hakim, F. O. Finkelstein, and E. Lacson, "First-year outcomes of incident peritoneal dialysis patients in the United States," American Journal of Kidney Diseases, vol. 64, no. 5, pp. 761-769, 2014.

[140] A. Rajaeefard, A. Rezaianzadeh, S. Sarvandian, and J. Roozbeh, "Analyzing the long-term survival of the patients undergoing peritoneal dialysis in the peritoneal dialysis center in Shiraz, 2002-2011," Saudi Journal of Kidney Diseases and Transplantation, vol. 27, no. 6, pp. 1211-1216, 2016.

[141] D. L. Regidor, J. D. Kopple, C. P. Kovesdy et al., "Associations between changes in hemoglobin and administered erythropoiesis-stimulating agent and survival in hemodialysis patients," Journal of the American Society of Nephrology, vol. 17, no. 4, pp. 1181-1191, 2006.

[142] T. L. Roberts, R. N. Foley, E. D. Weinhandl, D. T. Gilbertson, and A. J. Collins, "Anaemia and mortality in haemodialysis patients: Interaction of propensity score for predicted anaemia and actual haemoglobin levels," Nephrology Dialysis Transplantation, vol. 21, no. 6, pp. 1652-1662, 2006.

[143] B. M. Robinson, M. M. Joffe, J. S. Berns, R. L. Pisoni, F. K. Port, and H. I. Feldman, "Anemia and mortality in hemodialysis patients: accounting for morbidity and treatment variables updated over time," Kidney International, vol. 68, no. 5, pp. 2323-2330, 2005.

[144] K. Rossing, P. K. Christensen, P. Hovind, L. Tarnow, P. Rossing, and H.-H. Parving, "Progression of nephropathy in type 2 diabetic patients," Kidney International, vol. 66, no. 4, pp. 1596-1605, 2004

[145] M. A. Sabe, E. A. Burdmann, A. S. Desai et al., "Coronary artery disease is a predictor of progression to dialysis in patients with chronic kidney disease, type 2 diabetes mellitus, and anemia: an analysis of the trial to reduce cardiovascular events with aranesp therapy (TREAT)," Journal of the American Heart Association, vol. 5, no. 4, 2016.

[146] J. Santos, I. Fonseca, J. Malheiro et al., "End-stage renal disease versus death in a Portuguese cohort of elderly patients: an approach using competing event analysis," Journal of Investigative Medicine, vol. 65, no. 7, pp. 1041-1048, 2017.

[147] P. R. Santos, A. D. M. Melo, M. M. B. C. Lima et al., "Mortality risk in hemodialysis patients according to anemia control and erythropoietin dosing," Hemodialysis International, vol. 15, no. 4, pp. 493-500, 2011.

[148] Y. Sato, S. Fujimoto, T. Konta et al., "Anemia as a risk factor for all-cause mortality: obscure synergic effect of chronic kidney disease," Clinical and Experimental Nephrology, vol. 22, no. 2, pp. 388-394, 2018.

[149] T. Sato, S. Yamauchi, A. Yoshihisa et al., "Distinct prognostic factors in patients with chronic heart failure and chronic kidney disease," International Heart Journal, vol. 54, no. 5, pp. 311-317, 2013.

[150] S. Sawhney, O. Djurdjev, K. Simpson, A. Macleod, and A. Levin, "Survival and dialysis initiation: comparing British Columbia and Scotland registries," Nephrology Dialysis Transplantation, vol. 24, no. 10, pp. 3186-3192, 2009.

[151] E. B. Schroeder, X. Yang, M. L. Thorp et al., "Predicting 5year risk of RRT in stage 3 or 4 CKD: development and external validation," Clinical Journal of the American Society of Nephrology, vol. 12, no. 1, pp. 87-94, 2017.

[152] G. Selim, N. Ivanovski, K. Zafirovska et al., "Inflammation and anaemia as predictors of cardiovascular mortality in hemodialysis patients," Hippokratia, vol. 11, no. 1, pp. 39-43, 2007.

[153] G. Selim, O Stojceva-Taneva, A Sikole et al., "Association between haemoglobin level and all-cause mortality in haemodialysis patients: the link with inflammation and malnutrition," Prilozi, vol. 28, no. 1, pp. 81-95, 2007.

[154] K. S. Servilla, A. K. Singh, W. C. Hunt et al., "Anemia management and association of race with mortality and hospitalization in a large not-for-profit dialysis organization," American Journal of Kidney Diseases, vol. 54, no. 3, pp. 498-510, 2009.

[155] L. Shema-Didi, L. Ore, R. Geron, and B. Kristal, "Is anemia at hospital admission associated with in-hospital acute kidney injury occurrence?" Nephron Clinical Practice, vol. 115, no. 2, pp. c168-c176, 2010. 
[156] Y. Shimizu, S. Sato, J. Koyamatsu et al., “Associations between renal impairment and anemia in older, rural Japanese men: the Nagasaki Island study," Journal of physiological anthropology, vol. 33, no. 7, 2014.

[157] J. Shiraishi, Y. Kohno, T. Nakamura et al., "Prognostic impact of chronic kidney disease and anemia at admission on in-hospital outcomes after primary percutaneous coronary intervention for acute myocardial infarction," International Heart Journal, vol. 55, no. 4, pp. 301-306, 2014.

[158] A. K. Singh, L. Szczech, K. L. Tang et al., "Correction of anemia with epoetin alfa in chronic kidney disease," New England Journal of Medicine, vol. 355, no. 20, pp. 2085-2098, 2006.

[159] H. Skali, H.-H. Parving, P. S. Parfrey et al., "Stroke in patients with type 2 diabetes mellitus, chronic kidney disease, and anemia treated with darbepoetin alfa," Circulation, vol. 124, no. 25, pp. 2903-2908, 2011.

[160] K.-K. Song, D.-L. Zhao, Y.-D. Wang et al., "Analysis of factors associated with death in maintenance hemodialysis patients," Chinese Medical Journal, vol. 130, no. 8, pp. 885-891, 2017.

[161] D. N. Spigolon, T. P. de Moraes, A. E Figueiredo et al., "Impact of pre-dialysis care on clinical outcomes in peritoneal dialysis patients," American Journal of Nephrology, vol. 43, no. 2, pp. 104-111, 2016.

[162] L. A. Stevens, S. Li, M. Kurella Tamura et al., "Comparison of the CKD Epidemiology Collaboration (CKD-EPI) and Modification of Diet in Renal Disease (MDRD) study equations: risk factors for and complications of CKD and mortality in the Kidney Early Evaluation Program (KEEP)," American Journal of Kidney Diseases, vol. 57, no. 3, pp. S9-S16, 2011.

[163] P. E. Stevens, D. J. O’Donoghue, S. de Lusignan et al., "Chronic kidney disease management in the United Kingdom: NEOERICA project results," Kidney International, vol. 72, no. 1, pp. 92-99, 2007.

[164] P. E. Stevens, G. Schernthaner, S. Raptis, C. Wanner, A. Scherhag, and N. Lameire, "Characteristics, cardiovascular comorbidity and medicines management in patients with type 2 diabetes and CKD: Results of the IRIDIEM study," Kidney and Blood Pressure Research, vol. 33, no. 2, pp. 119-128, 2010.

[165] M. Stosovic, M. Stanojevic, S. Simic-Ogrizovic, D. Jovanovic, and L. Djukanovic, "The predictive value of anthropometric parameters on mortality in haemodialysis patients," $\mathrm{Ne}$ phrology Dialysis Transplantation, vol. 26, no. 4, pp. 13671374, 2011.

[166] E. Streja, C. P. Kovesdy, S. Greenland et al., "Erythropoietin, iron depletion, and relative thrombocytosis: a possible explanation for hemoglobin-survival paradox in hemodialysis," American Journal of Kidney Diseases, vol. 52, no. 4, pp. 727-736, 2008.

[167] G. Sturm, C. Lamina, E. Zitt et al., "Sex-specific association of time-varying haemoglobin values with mortality in incident dialysis patients," Nephrology Dialysis Transplantation, vol. 25, no. 8, pp. 2715-2722, 2010.

[168] C.-C. Szeto, B. C.-H. Kwan, K.-M. Chow, W.-F. Pang, C.-B. Leung, and P. K.-T. Li, "Haemoglobin variability in Chinese pre-dialysis CKD patients not receiving erythropoietin," Nephrology Dialysis Transplantation, vol. 26, no. 9, pp. 2919-2924, 2011.

[169] F. I. R. Teixeira, M. L. H. Lopes, G. A. dos Santos Silva, and R. F. Santos, "Survival of hemodialysis patients at a university hospital," Jornal Brasileiro de Nefrologia, vol. 37, no. 1, pp. 64-71, 2015.

[170] S. Thijssen, L. Usvyat, and P. Kotanko, "Prediction of mortality in the first two years of hemodialysis: results from a validation study," Blood Purification, vol. 33, no. 1-3, pp. 165-170, 2012.

[171] M. L. Thorp, E. S. Johnson, X. Yang, A. F. Petrik, R. Platt, and D. H. Smith, "Effect of anaemia on mortality, cardiovascular hospitalizations and end-stage renal disease among patients with chronic kidney disease," Nephrology, vol. 14, no. 2, pp. 240-246, 2009.

[172] T. Toida, Y. Sato, H. Komatsu, K. Kitamura, and S. Fujimoto, "Relationship between hemoglobin levels corrected by interdialytic weight gain and mortality in Japanese hemodialysis patients: Miyazaki dialysis cohort study," PLoS One, vol. 12, no. 1, Article ID e0169117, 2017.

[173] G. Tripepi, F. Mattace-Raso, F. Rapisarda et al., “Traditional and nontraditional risk factors as predictors of cerebrovascular events in patients with end stage renal disease," Journal of Hypertension, vol. 28, no. 12, pp. 2468-2474, 2010.

[174] Y. Tsubakihara, T. Akizawa, M. Iwasaki, and R. Shimazaki, "High hemoglobin levels maintained by an erythropoiesisstimulating agent improve renal survival in patients with severe renal impairment," Therapeutic Apheresis and Dialysis, vol. 19, no. 5, pp. 457-465, 2015.

[175] Y. Tsubakihara, F. Gejyo, S. Nishi et al., "High target hemoglobin with erythropoiesis-stimulating agents has advantages in the renal function of non-dialysis chronic kidney disease patients," Therapeutic Apheresis and Dialysis, vol. 16, no. 6, pp. 529-540, 2012.

[176] H. Ueda, E. Ishimura, T. Shoji et al., "Factors affecting progression of renal failure in patients with type 2 diabetes," Diabetes Care, vol. 26, no. 5, pp. 1530-1534, 2003.

[177] R. Vaiciuniene, V. Kuzminskis, E. Ziginskiene, and K. Petruliene, "Risk factors for cardiovascular hospitalization in hemodialysis patients," Medicina, vol. 46, no. 8, pp. 544-549, 2010.

[178] M. Van Diepen, O. M. Dekkers, J. I. Rotmans et al., "Predicting mortality in patients with diabetes starting dialysis," PLoS One, vol. 9, no. 3, Article ID e89744, 2014.

[179] J. Varas, R. Ramos, P. Aljama et al., "Relationships between iron dose, hospitalizations and mortality in incident haemodialysis patients: a propensity-score matched approach," Nephrology Dialysis Transplantation, vol. 33, no. 1, pp. 160-170, 2018.

[180] E. Vazquez, C. Sanchez-Perales, F. Garcia-Garcia et al., "Atrial fibrillation in incident dialysis patients," Kidney International, vol. 76, no. 3, pp. 324-330, 2009.

[181] P. Vejakama, A. Thakkinstian, A. Ingsathit, P. Dhanakijcharoen, and J. Attia, "Prognostic factors of allcause mortalities in continuous ambulatory peritoneal dialysis: a cohort study," BMC Nephrology, vol. 14, no. 1, 2013.

[182] N. Voormolen, D. C. Grootendorst, T. A. J. Urlings et al., "Prevalence of anemia and its impact on mortality and hospitalization rate in predialysis patients," Nephron Clinical Practice, vol. 115, no. 2, pp. c133-c141, 2010.

[183] M. Wagner, A. Alam, J. Zimmermann et al., "Endogenous erythropoietin and the association with inflammation and mortality in diabetic chronic kidney disease," Clinical Journal of the American Society of Nephrology, vol. 6, no. 7, pp. 1573-1579, 2011

[184] M. Wagner, D. Ansell, D. M. Kent et al., "Predicting mortality in incident dialysis patients: an analysis of the United 
Kingdom renal registry," American Journal of Kidney Diseases, vol. 57, no. 6, pp. 894-902, 2011.

[185] A. M. Walker, G. Schneider, J. Yeaw, B. Nordstrom, S. Robbins, and D. Pettitt, "Anemia as a predictor of cardiovascular events in patients with elevated serum creatinine," Journal of the American Society of Nephrology, vol. 17, no. 8, pp. 2293-2298, 2006.

[186] D. E. Weiner, H. Tighiouart, E. F. Elsayed et al., "The relationship between nontraditional risk factors and outcomes in individuals with stage 3 to $4 \mathrm{CKD}$," American Journal of Kidney Diseases, vol. 51, no. 2, pp. 212-223, 2008.

[187] D. E. Weiner, H. Tighiouart, P. T. Vlagopoulos et al., "Effects of anemia and left ventricular hypertrophy on cardiovascular disease in patients with chronic kidney disease," Journal of the American Society of Nephrology, vol. 16, no. 6, pp. 1803-1810, 2005.

[188] E. D. Weinhandl, Y. Peng, D. T. Gilbertson, B. D. Bradbury, and A. J. Collins, "Hemoglobin variability and mortality: confounding by disease severity," American Journal of Kidney Diseases, vol. 57, no. 2, pp. 255-265, 2011.

[189] I. W. Wu, K. H. Hsu, C. C. Lee et al., "Re-evaluating the predictive roles of metabolic complications and clinical outcome according to eGFR levels-a four-years prospective cohort study in Taiwan," BMC Nephrology, vol. 14, no. 1, 2013.

[190] R. Xu, M. Zhuo, Z. Yang, and J. Dong, "Experiences with assisted peritoneal dialysis in China," Peritoneal Dialysis International: Journal of the International Society for Peritoneal Dialysis, vol. 32, no. 1, pp. 94-101, 2012.

[191] T. Yamamoto, M. Miyazaki, M. Nakayama et al., "Impact of hemoglobin levels on renal and non-renal clinical outcomes differs by chronic kidney disease stages: the Gonryo study," Clinical and Experimental Nephrology, vol. 20, no. 4, pp. 595-602, 2016.

[192] X. Yang, R. C. Ma, W. Y. So et al., "Impacts of chronic kidney disease and albuminuria on associations between coronary heart disease and its traditional risk factors in type 2 diabetic patients-the Hong Kong diabetes registry," Cardiovascular Diabetology, vol. 6, 2007.

[193] W. Yang, R. K. Israni, S. M. Brunelli, M. M. Joffe, S. Fishbane, and H. I. Feldman, "Hemoglobin variability and mortality in ESRD," Journal of the American Society of Nephrology, vol. 18, no. 12, pp. 3164-3170, 2007.

[194] X. Yang, C. Yi, X. Liu et al., "Clinical outcome and risk factors for mortality in Chinese patients with diabetes on peritoneal dialysis: a 5-year clinical cohort study," Diabetes Research and Clinical Practice, vol. 100, no. 3, pp. 354-361, 2013.

[195] K. E. Yeates, D. C. Mendelssohn, J. Ethier et al., "Optimizing hemodialysis practices in Canada could improve patient survival," CANNT Journal, vol. 17, no. 2, pp. 22-34, 2007.

[196] R. Yotsueda, S. Tanaka, M. Taniguchi et al., "Hemoglobin concentration and the risk of hemorrhagic and ischemic stroke in patients undergoing hemodialysis: the Q-cohort study," Nephrology Dialysis Transplantation, vol. 33, no. 5, pp. 856-864, 2018.

[197] F. Zhang, H. Liu, X. Gong et al., "Risk factors for mortality in Chinese patients on continuous ambulatory peritoneal dialysis," Peritoneal Dialysis International: Journal of the International Society for Peritoneal Dialysis, vol. 35, no. 2, pp. 199-205, 2015.

[198] E. Ziginskiene, V. Kuzminskis, K. Petruliene, R. Vaiciuniene, A. Stankuviene, and I. A. Bumblyte, "Renal anemia control in Lithuania: influence of local conditions and local guidelines," The Scientific World Journal, vol. 2013, pp. 1-8, 2013.
[199] E. Zitt, G. Sturm, F. Kronenberg et al., "Iron supplementation and mortality in incident dialysis patients: an observational study," PLoS One, vol. 9, no. 12, 2014.

[200] G. Zoppini, G. Targher, M. Chonchol et al., "Anaemia, independent of chronic kidney disease, predicts all-cause and cardiovascular mortality in type 2 diabetic patients," Atherosclerosis, vol. 210, no. 2, pp. 575-580, 2010.

[201] S. C. Jones, D. Smith, S. Nag et al., "Prevalence and nature of anaemia in a prospective, population-based sample of people with diabetes: Teesside anaemia in diabetes (TAD) study," Diabetic Medicine, vol. 27, no. 6, pp. 655-659, 2010.

[202] M. E. Stauffer and T. Fan, "Prevalence of anemia in chronic kidney disease in the United States," PLoS One, vol. 9, no. 1, Article ID e84943, 2014.

[203] I. Idris, H. Tohid, N. A. Muhammad et al., "Anaemia among primary care patients with type 2 diabetes mellitus (T2DM) and chronic kidney disease (CKD): a multicentred crosssectional study," BMJ Open, vol. 8, no. 12, Article ID e025125, 2018.

[204] Y. Li, H. Shi, W.-M. Wang et al., "Prevalence, awareness, and treatment of anemia in Chinese patients with nondialysis chronic kidney disease," Medicine, vol. 95, no. 24, Article ID e3872, 2016.

[205] Kidney Disease: Improving Global Outcomes (KDIGO) Anemia Work Group, "KDIGO clinial practice guideline for anemia in chronic kidney disease," Kidney International Supplements, vol. 2, no. 4, pp. 279-335, 2012.

[206] W. M. Bernhardt, M. S. Wiesener, P. Scigalla et al., "Inhibition of prolyl hydroxylases increases erythropoietin production in ESRD," Journal of the American Society of Nephrology, vol. 21, no. 12, pp. 2151-2156, 2010.

[207] J. Zaritsky, B. Young, H.-J. Wang et al., "Hepcidin-a potential novel biomarker for iron status in chronic kidney disease," Clinical Journal of the American Society of $\mathrm{Ne}$ phrology, vol. 4, no. 6, pp. 1051-1056, 2009.

[208] K. Tsuchiya and K. Nitta, "Hepcidin is a potential regulator of iron status in chronic kidney disease," Therapeutic Apheresis and Dialysis, vol. 17, no. 1, pp. 1-8, 2013.

[209] N. Ueda and K. Takasawa, "Impact of inflammation on ferritin, hepcidin and the management of iron deficiency anemia in chronic kidney disease," Nutrients, vol. 10, no. 9, 2018.

[210] M. Lehtihet, Y. Bonde, L. Beckman et al., "Circulating hepcidin-25 is reduced by endogenous estrogen in humans," PLoS One, vol. 11, no. 2, Article ID e0148802, 2016.

[211] E. Bachman, R. Feng, T. Travison et al., "Testosterone suppresses hepcidin in men: a potential mechanism for testosterone-induced erythrocytosis," The Journal of Clinical Endocrinology \& Metabolism, vol. 95, no. 10, pp. 4743-4747, 2010.

[212] J. Lea, D. Cheek, D. Thornley-Brown et al., "Metabolic syndrome, proteinuria, and the risk of progressive CKD in hypertensive African Americans," American Journal of Kidney Diseases, vol. 51, no. 5, pp. 732-740, 2008.

[213] S. Fishbane, "Anemia and cardiovascular risk in the patient with kidney disease," Heart Failure Clinics, vol. 4, no. 4, pp. 401-410, 2008.

[214] I. S. Anand, Y. Chandrashekhar, R. Ferrari, P. A. PooleWilson, and P. C. Harris, "Pathogenesis of oedema in chronic severe anaemia: studies of body water and sodium, renal function, haemodynamic variables, and plasma hormones," Heart, vol. 70, no. 4, pp. 357-362, 1993.

[215] F. Locatelli, L. Del Vecchio, and P. Pozzoni, "Anemia and cardiovascular risk: the lesson of the CREATE Trial,” Journal 
of the American Society of Nephrology, vol. 17, no. 12, pp. S262-S266, 2006.

[216] A. K. Singh, L. Szczech, K. L. Tang et al., "Correction of anemia with epoetin alfa in chronic kidney disease," New England Journal of Medicine, vol. 355, no. 20, pp. 2085-2098, 2006.

[217] T. B. Drüeke, F. Locatelli, N. Clyne et al., "Normalization of hemoglobin level in patients with chronic kidney disease and anemia," New England Journal of Medicine, vol. 355, no. 20, pp. 2071-2084, 2006.

[218] M. A. Pfeffer, E. A. Burdmann, C. Y. Chen et al., "A trial of darbepoetin alfa in type 2 diabetes and chronic kidney disease," The New England Journal of Medicine, vol. 361, no. 21, pp. 2019-2032, 2009.

[219] P. A. McCullough, H. X. Barnhart, J. K. Inrig et al., "Cardiovascular toxicity of epoetin-alfa in patients with chronic kidney disease," American Journal of Nephrology, vol. 37, no. 6, pp. 549-558, 2013. 